\title{
Altered Expression Ratio of Actin-Binding Gelsolin Isoforms Is a Novel Hallmark of Mitochondrial OXPHOS Dysfunction
}

\author{
Alberto García-Bartolomé ${ }^{1,+}$, Ana Peñas ${ }^{1,+}$, María Illescas ${ }^{1}$, Verónica Bermejo ${ }^{1}$, \\ Sandra López-Calcerrada ${ }^{1}$, Rafael Pérez-Pérez ${ }^{1}{ }^{1}$, Lorena Marín-Buera ${ }^{1}$, \\ Cristina Domínguez-González ${ }^{1,2,3}$, Joaquín Arenas ${ }^{1,2}$, Miguel A. Martín 1,2 (D) \\ and Cristina Ugalde ${ }^{1,2, * \mathbb{D}}$ \\ 1 Laboratorio de Enfermedades Mitocondriales y Neurometabólicas, Instituto de Investigación Hospital 12 de \\ Octubre (i+12), 28041 Madrid, Spain; alberto7188@hotmail.com (A.G.-B.); anappdv.imas12@h12o.es (A.P.); \\ maria.illescas@hotmail.com (M.I.); vbermejo.imas12@h12o.es (V.B.); sandra.lopezcal@gmail.com (S.L.-C.); \\ rafaperez44@gmail.com (R.P.-P.); Lorena.marin@biolamina.com (L.M.-B.); c.dom.glez@gmail.com (C.D.-G.); \\ joaquin.arenas@salud.madrid.org (J.A.); mamcasanueva.imas12@h12o.es (M.A.M.) \\ 2 Centro de Investigación Biomédica en Red de Enfermedades Raras (CIBERER), U723 Madrid, Spain \\ 3 Neuromuscular Unit, Hospital Universitario 12 de Octubre, 28041 Madrid, Spain \\ * Correspondence: cugalde@h12o.es; Tel.: +34-91-779-2784; Fax: +34-91-390-8544 \\ + These authors equally contributed to this work.
}

Received: 30 May 2020; Accepted: 15 August 2020; Published: 19 August 2020

\begin{abstract}
Mitochondrial oxidative phosphorylation (OXPHOS) defects are the primary cause of inborn errors of energy metabolism. Despite considerable progress on their genetic basis, their global pathophysiological consequences remain undefined. Previous studies reported that OXPHOS dysfunction associated with complex III deficiency exacerbated the expression and mitochondrial location of cytoskeletal gelsolin (GSN) to promote cell survival responses. In humans, besides the cytosolic isoform, GSN presents a plasma isoform secreted to extracellular environments. We analyzed the interplay between both GSN isoforms in human cellular and clinical models of OXPHOS dysfunction. Regardless of its pathogenic origin, OXPHOS dysfunction induced the physiological upregulation of cytosolic GSN in the mitochondria (mGSN), in parallel with a significant downregulation of plasma GSN (pGSN) levels. Consequently, significantly high mGSN-to-pGSN ratios were associated with OXPHOS deficiency both in human cells and blood. In contrast, control cells subjected to hydrogen peroxide or staurosporine treatments showed no correlation between oxidative stress or cell death induction and the altered levels and subcellular location of GSN isoforms, suggesting their specificity for OXPHOS dysfunction. In conclusion, a high mitochondrial-to-plasma GSN ratio represents a useful cellular indicator of OXPHOS defects, with potential use for future research of a wide range of clinical conditions with mitochondrial involvement.
\end{abstract}

Keywords: mitochondria; OXPHOS dysfunction; oxidative stress; actin cytoskeleton; gelsolin isoforms; GSN; biomarker

\section{Introduction}

Mitochondria participate in a large variety of metabolic and physiological processes, such as lipid metabolism, iron-sulphur cluster biogenesis, hormone and reactive oxygen species (ROS) signaling, calcium buffering, and apoptosis, and importantly, they provide most of the energy (ATP) usable by cells through the oxidative phosphorylation (OXPHOS) system. The OXPHOS system is located in the mitochondrial inner membrane, and it is composed of five multiprotein enzyme 
complexes and two mobile electron carriers (ubiquinone and cytochrome $c$ ) that couple respiration to ATP synthesis: Complexes I to IV (CI-CIV) constitute the mitochondrial respiratory chain (MRC), which transfers electrons from $\mathrm{NADH}$ and $\mathrm{FADH}_{2}$ to molecular oxygen, with a parallel generation of a proton gradient across the mitochondrial inner membrane that is used by complex $\mathrm{V}$ for ATP synthesis [1]. Primary functional defects of the OXPHOS machinery are the leading cause of inborn errors of energy metabolism, involving more than 350 disorder-related genes [2]. Notably, OXPHOS dysfunction is likely involved in the pathogenesis of common clinical conditions, such as obesity and diabetes [3-5]; neurodegenerative conditions, like Alzheimer's or Parkinson's disease [6,7]; and may be crucial in cancer treatment $[8,9]$. Despite the wide knowledge on the molecular genetic origins of OXPHOS disorders [10], their underlying pathophysiological mechanisms remain mostly unknown. The diagnosis of OXPHOS diseases remains challenging due to their wide clinical heterogeneity, and research for specific and sensitive diagnostic tools based on serum biomarkers is currently active [10].

High-resolution differential proteomics applied to the diagnosis of OXPHOS deficiency previously identified potential therapeutic targets for mitochondrial disorders [11,12]. Particularly, analyses in primary skin fibroblasts from patients with mutations in BCS1L, encoding an assembly factor involved in the biogenesis of MRC complex III $[13,14]$, revealed a protein profile showing main alterations in energy metabolism, as well as in the structural organization of the cytoskeleton, regulation of gene expression, protein transport, and metabolic stress responses [12]. The most significantly upregulated protein was the cytosolic isoform of gelsolin (GSN), an $\sim 81-\mathrm{kDa}$ cytoskeletal protein that regulates the cap and severing of actin filaments in a calcium-dependent fashion [15]. Besides its role in actin filaments' remodeling, GSN plays a multifunctional regulatory role as a transcriptional coactivator, as well as a downstream effector of cell signaling on the crosstalk between the actin cytoskeleton and transmembrane receptors [16,17]. In humans, besides the cytosolic GSN isoform, there is a plasma isoform (pGSN) mainly secreted from muscle into the extracellular space, which can be easily detected in serum or plasma [18-20]. The human pGSN isoform, $\sim 86 \mathrm{kDa}$, contains a specific secretory signal peptide of 51 amino acids at its N-terminus (UniProtKB references P06396 and P06396-2), and a disulphide bond that confers additional stability in the extracellular environment [21]. pGSN plays a relevant role in cardiovascular disease, as it is part of the extracellular actin scavenger system (EASS) responsible for rapid severing and removal of actin filaments released from tissue necrosis into the bloodstream, by sequestering monomeric actin and increasing its clearance from the circulation [22,23]. Both isoforms are encoded by alternative splicing of GSN mRNAs, and maintain their ability to depolymerize actin filaments [24].

Mutations in the GSN gene have been linked to familial amyloidosis of Finnish type (FAF) or gelsolin amyloidosis [MIM\#105120], a rare, autosomal dominant hereditary amyloid polyneuropathy, mainly characterized by progressive cranial neuropathies, corneal lattice dystrophy, and sensory neuropathy [25]. This disorder is caused by the systemic aggregation and deposition of aberrant proteolytic fragments of pGSN mediated by matrix metalloproteases [26]. Moreover, altered expression of both GSN isoforms has been associated to a diversity of pathophysiological conditions. Due to its role in EASS, decreased pGSN levels result in detrimental effects caused by actin accumulation in the bloodstream: Increased blood viscosity affecting microvascular flow, platelet activation and aggregation, microvascular thrombosis, release of proinflammatory mediators, fibrinolysis impairment, and increased alpha-haemolysin production [24]. Thus, decreased pGSN levels were consistently reported in cardiovascular diseases, major trauma and injuries, diabetes [27], and in other relevant pathologies, such as Alzheimer's disease, rheumatoid arthritis, sepsis, liver failure, or cancer [17,24,28], to the point that pGSN has been proposed as a general biomarker of health prognosis [28]. In contrast, upregulation of cytosolic GSN expression mainly influences cytoskeletal turnover and dynamics, and was associated with ageing [29], Down syndrome [30], or heart failure [31,32]. Experimental evidence suggests that increased cytoplasmic GSN levels are triggered under oxidative stress conditions, such as lipid peroxidation [33,34], in the presence of calcium ionophores [35], upon hydrogen peroxide 
treatment via PKC activators [36], as well as in mouse HIF-1 knock-out (KO) fibroblasts subjected to hypoxia [37]. Studies in cancer cells showed that cytosolic GSN expression may impact the cellular redox milieu and cell survival by modulating intracellular $\mathrm{O}^{2 \cdot-} / \mathrm{H}_{2} \mathrm{O}_{2}$ levels, possibly by the interaction and suppression of superoxide dismutase 1 ( $\mathrm{Cu} / \mathrm{Zn} \mathrm{SOD})$ enzymatic activity $[38,39]$. Other studies in human cell lines with MRC complex III deficiency demonstrated the upregulation and location of GSN at the mitochondrial outer membrane (henceforth mitochondrial GSN or mGSN), where it interacts with the voltage-dependent anion channel (VDAC) to prevent the release of mitochondrial cytochrome $c$ into the cytosol and apoptotic cell death [40]. However, whether these GSN-mediated survival adaptations occur as a general response to oxidative stress or are specific to OXPHOS dysfunction remains largely unknown.

In this work, we analyzed the interplay between the cytosolic and plasma isoforms of GSN in human cellular models of OXPHOS deficiency and oxidative stress. Our results show that a high mitochondrial-to-plasma GSN ratio represents a useful indicator of OXPHOS system dysfunction in human cultured cells. Importantly, the mGSN:pGSN ratio was modulated by genetic manipulation of OXPHOS-deficient cell lines. These analyses were extrapolated to blood from patients with OXPHOS disorders, representing a promising proof of concept for future research on the diagnosis of these devastating pathologies.

\section{Materials and Methods}

\subsection{Cell Cultures and Treatments}

Primary skin fibroblasts were obtained from healthy donors (age and sex matched) and pediatric patients (P1-P4) with mutations in BCS1L that displayed MRC complex III deficiency [11]. Fibroblasts were cultured in $1 \mathrm{~g} / \mathrm{L}$ glucose-containing Dulbecco's modified Eagle's Medium (DMEM) (Invitrogen, ThermoFisher, UT, USA) supplemented with $10 \%$ fetal bovine serum (FBS), $100 \mathrm{IU} / \mathrm{mL}$ penicillin, and $100 \mathrm{IU} / \mathrm{mL}$ streptomycin at $37^{\circ} \mathrm{C}$ and $5 \% \mathrm{CO}_{2}$. Written informed consent was previously obtained from the parents of affected children.

Detailed pathophysiological characterization of OXPHOS deficiency was previously performed on the transmitochondrial cybrids and HEK293T cells used in our study [41-47]. The complex I-deficient cybrids (CI-KD) harbor a homoplasmic m.4681T >C mutation in the MT-ND2 subunit gene that leads to a severe complex I assembly defect due to a p.L71P substitution [41]. The complex III mutant cell line (CIII-KO) contains a homoplasmic 4-base pair deletion in the MT-CYB gene that affects the de novo synthesis of cytochrome $b$ and completely abolishes complex III activity $[42,43]$. The first complex IV mutant cell line (CIV-KO1) lacks CIV due to the homoplasmic m.6930G $>$ A transition in the MT-CO1 gene, which generates a stop codon leading to the loss of the last 170 amino acids of the COX1 polypeptide [44]. The second complex IV mutant cell line (CIV-KO2) lacks functional $\mathrm{CIV}$ due to the homoplasmic m.7896 G>A transition in the MT-CO2 gene, creating a stop codon that results in the loss of 123 amino acids at the C-terminus of the COX2 polypeptide [45]. The complex IV-deficient COX18-KO HEK293T cells were previously generated by TALEN-based gene editing [47]. Transmitochondrial cybrids, control 143B-TK- cells, and HEK293T cells were cultured in $4.5 \mathrm{~g} / \mathrm{L}$ glucose-containing DMEM medium (Invitrogen) supplemented with 10\% FBS, $50 \mu \mathrm{g} / \mathrm{mL}$ uridine, and $100 \mathrm{IU} / \mathrm{mL}$ penicillin/streptomycin.

To induce a general blockage of OXPHOS function, cells were treated for up to $48 \mathrm{~h}$ with the MRC complex III activity inhibitor antimycin A (AA) at concentrations ranging between 2 and $500 \mathrm{nM}$. To analyze the effect of oxidative stress on GSN levels, control 143B-TK ${ }^{-}$cells were treated with 100, 200 , and $500 \mu \mathrm{M}$ hydrogen peroxide $\left(\mathrm{H}_{2} \mathrm{O}_{2}\right.$, Merck, Darmstadt, Germany) for 6, 24, and $36 \mathrm{~h}$ before harvesting, as previously described [36]. To induce apoptotic cell death, control cells were treated with 1 and $2 \mu \mathrm{M}$ staurosporine for 6,15 , and $24 \mathrm{~h}$. In all experiments, cells were balanced for passage number. 


\subsection{Blood Samples}

Blood samples were collected in EDTA anticoagulant tubes from 9 adult patients (P5-P13, Table 1) who were clinically, biochemically, and/or genetically diagnosed with MRC deficiency at Hospital Universitario 12 de Octubre (Madrid, Spain), as well as from 9 healthy individuals (C1-C9, Table 2). This study was approved by the institutional Ethics Committee at Hospital Universitario 12 de Octubre, and it is in accordance with the Declaration of Helsinki for Human Research.

Table 1. Clinical features of 9 adult patients with mitochondrial OXPHOS disease (MD).

\begin{tabular}{ccccccccc}
\hline No & Age & Sex & Genetics & $\begin{array}{c}\text { Clinical } \\
\text { Phenotype }\end{array}$ & $\begin{array}{c}\text { Enzyme } \\
\text { Defect }\end{array}$ & mGSN & pGSN & mGSN/pGSN \\
\hline P5 & 30 & M & $\begin{array}{c}\text { Single } \\
\text { deletion }\end{array}$ & CPEO & IV & 6.23 & 1.35 & 4.615 \\
\hline P6 & 38 & F & $\begin{array}{c}\text { Single } \\
\text { deletion }\end{array}$ & $\begin{array}{c}\text { CPEO }+ \\
\text { Myopathy }\end{array}$ & I, III, IV & 0.37 & 0.69 & 0.536 \\
\hline P7 & 48 & M & OPA1 & Neuropathy & I & 2.93 & 0.62 & 4.726 \\
\hline P8 & 53 & M & POLG & $\begin{array}{c}\text { Exercise } \\
\text { intolerance }\end{array}$ & I (mild) & 1.36 & 1.03 & 1.320 \\
\hline P9 & 35 & M & POLG & $\begin{array}{c}\text { Exercise } \\
\text { intolerance }\end{array}$ & III (mild) & 2.53 & 1.09 & 2.321 \\
\hline P10 & 58 & M & TK2 & Myopathy & Normal & 1.43 & 0.90 & 1.589 \\
\hline P11 & 29 & F & TK2 & Myopathy & I, III, IV & 3.91 & 1.05 & 3.724 \\
\hline P12 & 22 & M & $\begin{array}{c}M T-C O 3 \\
\text { m.9319A }>\text { G }\end{array}$ & Myopathy & I, III & 1.70 & 0.92 & 1.848 \\
\hline P13 & 45 & M & $\begin{array}{c}M T-T N \\
\text { m.5688T }>C\end{array}$ & Myopathy & Normal & 0.47 & 0.79 & 0.595 \\
\hline
\end{tabular}

$\mathrm{N}^{\circ}$ : Patient number; M: Male; F: Female; I: Complex I; III: Complex III; IV: Complex IV. Numerical values represent the densitometric signals of mitochondrial GSN (mGSN) quantified in three biological replicates, normalized using SDHA as loading control, and presented relative to the mean mGSN value of control samples (Table 2). Plasma GSN (pGSN) concentrations $(\mu \mathrm{g} / \mathrm{mL}$ ) were quantified in four experimental replicates and expressed relative to the mean pGSN value of control samples (Table 2).

Table 2. Characteristics of 9 healthy adult controls.

\begin{tabular}{cccccc}
\hline Control & Age & Sex & mGSN & pGSN & mGSN/pGSN \\
\hline C1 & 22 & M & 0.306 & 1.06 & 0.289 \\
\hline C2 & 33 & M & 0.181 & 0.80 & 0.226 \\
\hline C3 & 38 & M & 1.160 & 1.00 & 1.160 \\
\hline C4 & 53 & M & 0.505 & 0.65 & 0.777 \\
\hline C5 & 56 & M & 0.430 & 1.03 & 0.417 \\
\hline C6 & 61 & M & 0.775 & 1.23 & 0.630 \\
\hline C7 & 33 & F & 0.349 & 1.08 & 0.323 \\
\hline C8 & 42 & F & 1.885 & 1.20 & 1.571 \\
\hline C9 & 61 & F & 2.223 & 1.15 & 1.933
\end{tabular}

M: Male; F: Female. Numerical values represent the densitometric signals of mitochondrial GSN $(m G S N)$ quantified in three biological replicates, normalized using SDHA as loading control, and presented relative to the mean control value. Plasma GSN (pGSN) concentrations $(\mu \mathrm{g} / \mathrm{mL})$ were quantified in four experimental replicates and expressed relative to the mean control value. 


\subsection{Peripheral Blood Mononuclear Cells and Plasma Separation}

Peripheral blood mononuclear cells (PBMCs) were extracted using Ficoll-Paque PLUS density centrifugation (GE Healthcare, Barcelona, Spain). In total, $3 \mathrm{~mL}$ of Ficoll-Paque media were added to a centrifuge tube and $6 \mathrm{~mL}$ of diluted blood samples were carefully layered onto the Ficoll-Paque media solution without mixing. Next, the tube was centrifuged at $750 \mathrm{~g}$ for $20 \mathrm{~min}$ at RT (brake turned off). The upper layer containing plasma and platelets was drawn off and centrifuged at $2000 \mathrm{~g}$ for $10 \mathrm{~min}$. Supernatant (plasma) was aliquoted and immediately stored at $-80^{\circ} \mathrm{C}$. The undisturbed layer corresponding to mononuclear cells was transferred to a sterile centrifuge tube; PBMCs were washed with phosphate-buffered saline (PBS), aliquoted, and stored at $-80^{\circ} \mathrm{C}$.

\subsection{Mitochondrial Respiration}

Basal oxygen consumption rates were measured with an XF24 Extracellular Flux Analyzer (Seahorse Bioscience, Agilent, CA, USA). The day before the experiment, around $9 \times 10^{4}$ cells per well were seeded in order to obtain 150-200 $\mu \mathrm{g}$ of protein per well on the day of the experiment. Cells were then incubated for $1 \mathrm{~h}$ in unbuffered DMEM supplemented with $4.5 \mathrm{~g} / \mathrm{L}$ glucose (cybrids) or $1 \mathrm{~g} / \mathrm{L}$ glucose (fibroblasts), $1 \mathrm{mM}$ sodium pyruvate, and $2 \mathrm{mM}$ glutamine at $37^{\circ} \mathrm{C}$ in a $\mathrm{CO}_{2}$-free incubator. Initially, baseline cellular OCR was measured, and mitochondrial basal respiration was calculated by subtracting non-mitochondrial respiration upon addition of the mitochondrial inhibitors rotenone and antimycin A at a $1 \mu \mathrm{M}$ final concentration. In all experiments, the protein concentration per well was determined using the Pierce BCA Protein Assay Kit (ThermoFisher, IL, USA) after cell lysis in extraction buffer, and was used to calibrate the oxygen consumption data ( $\mathrm{pmol} / \mathrm{min} / \mathrm{mg})$.

\subsection{Intracellular ROS Levels}

Concentrations of reactive oxygen species (ROS) were determined with the Amplex Red Hydrogen Peroxide/Peroxidase Assay kit (Molecular Probes, ThermoFisher, UK), according to the manufacturer's guidelines. Briefly, cybrid cultures were incubated for $30 \mathrm{~min}$ at $37^{\circ} \mathrm{C}$ in the dark with a reaction mix containing the Amplex red reagent and HRP peroxidase. Absorbance was measured at $560 \mathrm{~nm}$ in an Epoch Microplate Spectrophotometer (Biotek, VT, USA), and values were normalized for the total amount of protein per well.

\subsection{Isolation of Mitochondrial Fractions from Human Cells}

Cultured cells and PBMCs were harvested and mitochondrial fractions were isolated with the Mitochondria Isolation Kit human MACS (Miltenyi Biotec, Gladbach, Germany), according to the manufacturer's guidelines.

\subsection{Purification of Secreted Proteins from Cultured Cells}

Cells were cultured for $24 \mathrm{~h}$ in DMEM medium without FBS supplementation. Extracellular media were harvested and the secreted protein extracts (secretomes) were concentrated using Amicon Ultra-15 tubes (Merck, Darmstadt, Germany) according to the manufacturer's guidelines. Briefly, secretomes were centrifuged at $4000 \mathrm{~g}$ for $10 \mathrm{~min}$, and the collected fraction was washed three times with cold PBS and resuspended in $100 \mu \mathrm{L}$ of extraction buffer $(20 \mathrm{mM}$ HEPES NaOH pH 7.4, $150 \mathrm{mM}$ $\mathrm{NaCl}, 10 \%$ glycerol, $1 \% \mathrm{Tx}-100)$ and Protease Inhibitor Cocktail Tablets (Roche, Basel, Switzerland).

\subsection{SDS-PAGE Electrophoresis}

Protein concentrations were measured using the micro BCA protein assay (ThermoFisher, IL, USA). Whole-cell and mitochondrial protein extracts $(15 \mu \mathrm{g})$ were resolved on conventional 10\% SDS-PAGE gels and transferred to PROTRAN ${ }^{\circledR \circledR}$ nitrocellulose membranes (Whatman GmbH, GE Healthcare Life Sciences, Germany). Secreted protein extracts $(25 \mu \mathrm{g})$ were separated either on conventional $10 \%$ SDS-PAGE gels and visualized by Coomassie staining (Fisher Bioreagents, Geel, Belgium), or, 
alternatively, they were resolved on 10\% Mini-Protein TGX Stain Free Precast Gels (Bio-Rad, Mory, France) followed by quantification of the fluorescent protein signals in a ChemiDoc ${ }^{\mathrm{TM}} \mathrm{MP}$ Imager (Bio-Rad, CA, USA).

\subsection{Blue Native Electrophoresis and In-Gel Activity Assays}

Mitochondrial pellets were isolated from $\mathrm{T}_{175}$ cell culture flasks or $15-\mathrm{cm}$ Petri dishes (ThermoFisher, Madrid, Spain). Pre-cast NativePAGE ${ }^{\mathrm{TM}} 3-12 \%$ Bis-Tris gels (ThermoFisher, UK) were loaded with 60-80 $\mu \mathrm{g}$ of mitochondrial protein and processed for blue native electrophoresis (BN-PAGE) and in-gel activity (IGA) assays as described before [48]. After electrophoresis, proteins were transferred to nitrocellulose membranes at $40 \mathrm{~V}$ overnight and probed with antibodies.

\subsection{Antibody Detection}

Immunoblotting was performed with primary antibodies raised against human GSN, complex I NDUFA9 subunit, complex II SDHA subunit, complex III CORE2 subunit (Abcam, Cambridge, UK), complex IV COX5B subunit (Santa Clara, TX, USA), or $\mu$-Actin (Sigma). Peroxidase-conjugated anti-mouse or anti-rabbit IgGs (Molecular Probes) were used as secondary antibodies. Immunoreactive bands were detected with ECL Prime Western Blotting Detection Reagent (Amersham Biosciences, UK) in a ChemiDoc ${ }^{\mathrm{TM}}$ MP Imager (Bio-Rad), and their optical densities were measured using the ImageLab $^{\mathrm{TM}}$ (Bio-Rad) and the ImageJ analysis software.

\subsection{GSN ELISA Analyses}

Plasma GSN (pGSN) concentrations were measured with a specific ELISA kit to GSN (Aviscera Bioscience Inc., Quimigen, CA, USA) in plasma samples previously diluted 1:8000 to 12,000 for pGSN detection, according to the manufacturer's guidelines.

\subsection{Data Analysis}

All experiments were performed at least in triplicate, unless otherwise indicated, and results were presented as mean \pm standard deviation (SD) values. Statistical $p$ values were obtained by application of the Mann-Whitney $U$ test using GraphPad and SPSS v21.0 programs.

\section{Results}

\subsection{Cytoplasmic GSN Is Upregulated and Targeted to Mitochondria as a General Response to OXPHOS Deficiency}

Previous studies in mitochondrial complex III (CIII)-deficient cell lines revealed a specific upregulation of cytosolic GSN and its localization to the mitochondrial outer membrane (mGSN), where it interacts with VDAC1 to promote protective antiapoptotic responses [12,40]. To discriminate whether this phenomenon is specific to CIII deficiency, rather than occurring as a general response to OXPHOS enzyme defects, we analyzed control and mutant cybrids with different types of OXPHOS deficiency (Figure 1). All cybrid clones contained the nuclear background from 143B TK ${ }^{-}$rho zero cells [49], and were populated with mitochondria harboring homoplasmic mutations in the CI MT-ND2, CIII MT-CYB, CIV MT-CO1, and CIV MT-CO2 genes (CI-KD, CIII-KO, CIV-KO1, and CIV-KO2, respectively) $[41,44,45,50]$. Blue native electrophoresis followed by CI-IGA assay or by Western blot with different antibodies recognizing specific subunits from complexes I-IV (Figure 1A) revealed severe structural alterations of the MRC complexes I, III, or IV and of the mitochondrial supercomplexes (SCs) in the mutant cybrids relative to their isogenic controls. Mitochondrial basal respiration analyses (Figure 1B) confirmed the previously described functional abolishment of the OXPHOS system as a consequence of the structural loss of functional MRC complexes I, III, or IV in the mutants [41-43,51,52].

Then, we analyzed by Western blot and immunoblotting the steady-state levels of cytosolic GSN in whole-cell lysates and in purified mitochondrial fractions from control and mutant cybrids (Figure 2A). GSN signals were quantified and normalized relative to $\beta$-actin in whole-cell lysates, and normalized 
relative to the complex II SDHA subunit in purified mitochondria. Densitometric analyses of four independent experiments confirmed a significant increase of GSN levels in whole cells * $(p<0.05)$, as well as a highly significant increase in the mitochondrial fractions ${ }^{* * *}(p<0.001)$ of all mutants relative to control cybrids (Table 3). These results indicate that mGSN levels are preferentially increased in cybrid cells with OXPHOS dysfunction.

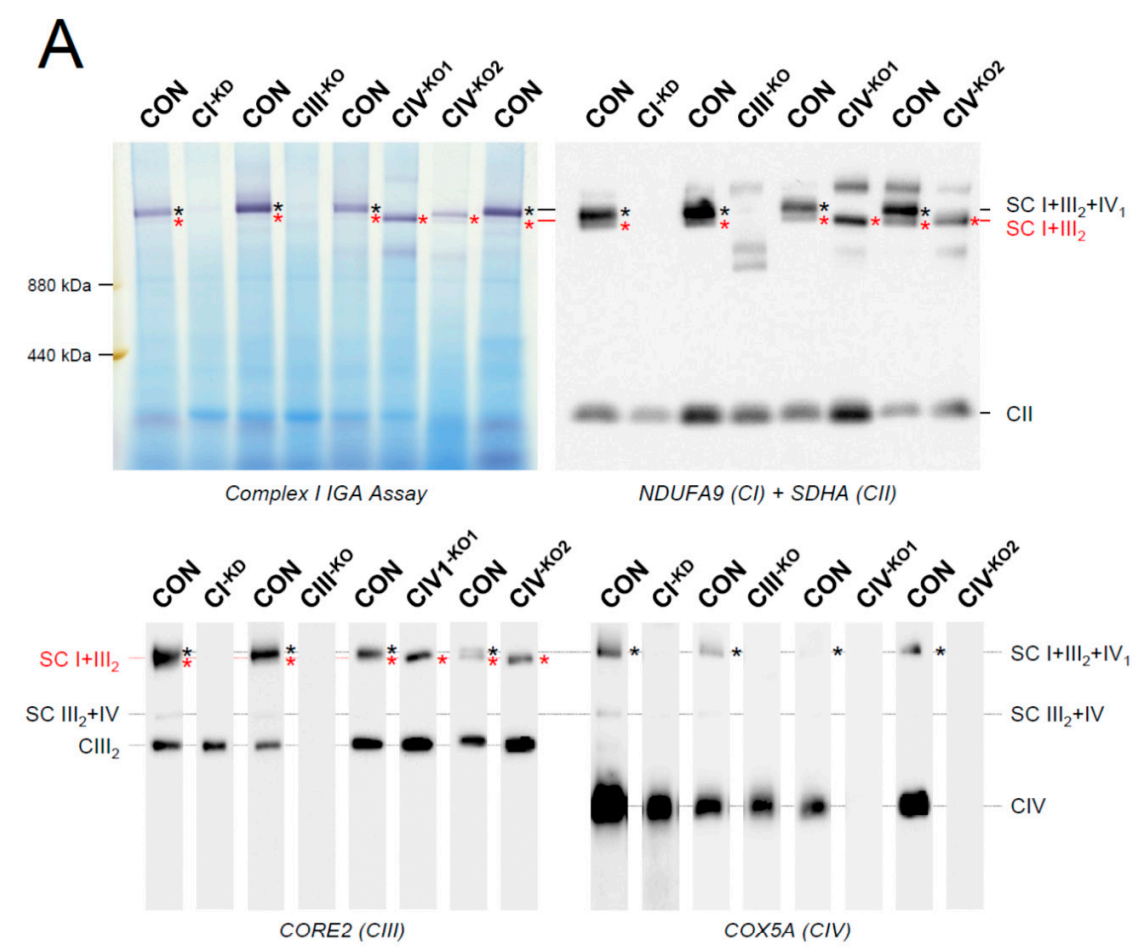

B

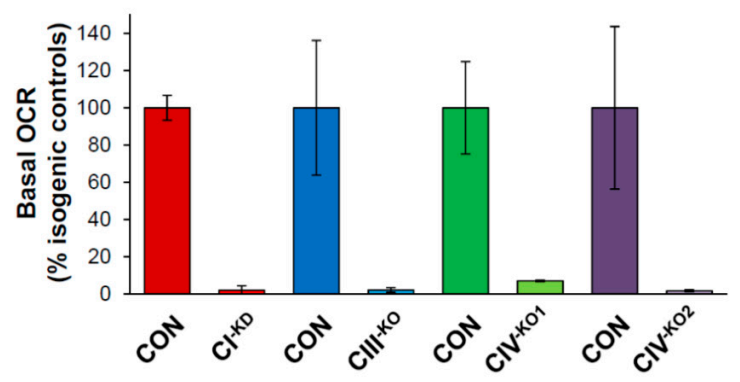

Figure 1. Structural and functional defects of the respiratory chain in mutant transmitochondrial cybrids. (A) Mitochondria were isolated from isogenic controls $(\mathrm{CON})$ and mutant cybrids harboring homoplasmic mutations in the mitochondrial MT-ND2 (CI $\left.{ }^{-\mathrm{KD}}\right), M T-C Y B\left(\mathrm{CIII}^{-\mathrm{KO}}\right), M T-\mathrm{CO} 1\left(\mathrm{CIV} 1^{-\mathrm{KO}}\right)$, and MT-CO2 $\left(\mathrm{CIV}^{-\mathrm{KO}}\right)$ genes. Digitonized mitochondria (digitonin-to-protein ratio of 4:1) were analyzed by BN-PAGE, and supercomplexes were visualized by complex I in-gel activity (IGA) assay and Western blot with the indicated antibodies that recognize subunits from MRC complexes I-IV. The relative position of the molecular weight marker is indicated on the left of the upper panels. The identity of the respiratory chain supercomplexes (SCs) is I $+\mathrm{III}_{2}+\mathrm{IV}_{1}$, $\mathrm{SC}$ containing complexes I, $\mathrm{III}_{2}$ and IV; I + $\mathrm{III}_{2}$, SC containing complexes I and $\mathrm{III}_{2} ; \mathrm{III}_{2}+\mathrm{IV}$, SC containing complexes $\mathrm{III}_{2}$ and $\mathrm{IV}_{2} \mathrm{III}_{2}$, CIII dimer. (B) Mitochondrial basal oxygen consumption rates (OCR) were measured in control (CON) and mutant cybrids respiring in $4.5 \mathrm{~g} / \mathrm{L}$ glucose-containing medium. Three technical measurements per sample were performed in two independent experiments in the isogenic controls (CON) and the $\mathrm{CI}^{-\mathrm{KD}}, \mathrm{CIII}{ }^{-\mathrm{KO}}$, and $\mathrm{CIV}^{-\mathrm{KO}}$ cell lines, and once in the $\mathrm{CIV} 1^{-\mathrm{KO}}$ cybrids. Data are expressed as the mean \pm SD of the percentages of the isogenic control values. OCR values were calculated in pmol $\mathrm{O}_{2} \cdot \mathrm{min}^{-1} \cdot \mu \mathrm{g}$ protein ${ }^{-1}$ in all experiments. 

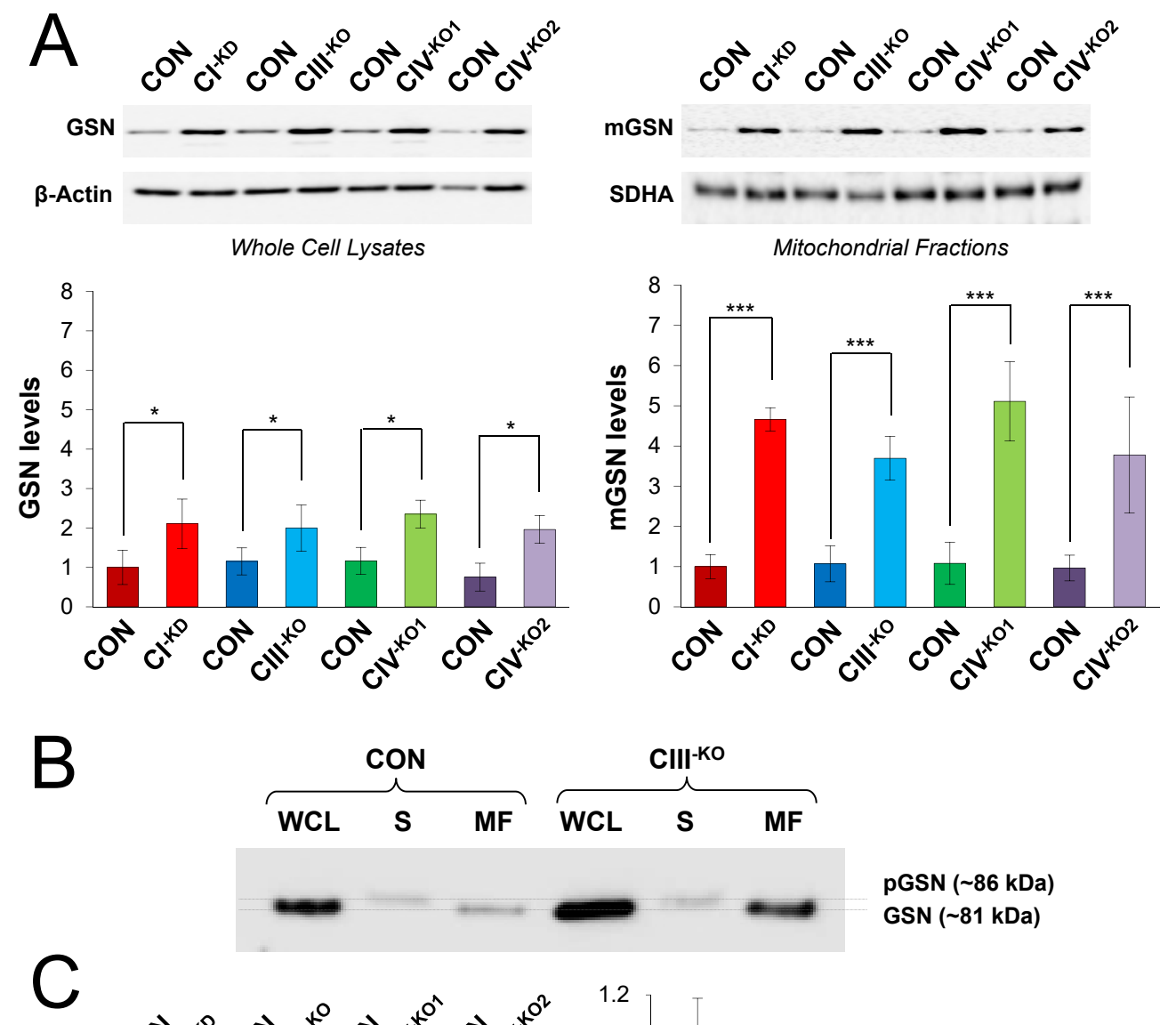

$\operatorname{pGSN}(\sim 86 \mathrm{kDa})$

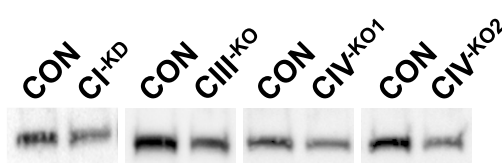

PGSN

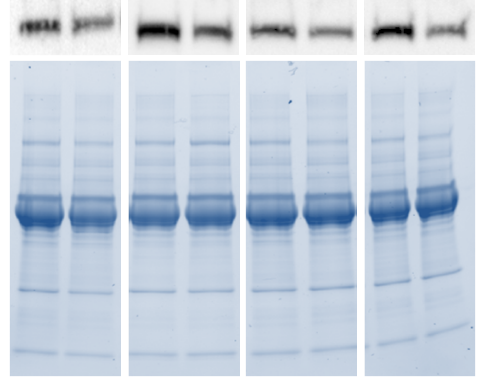

Secretomes

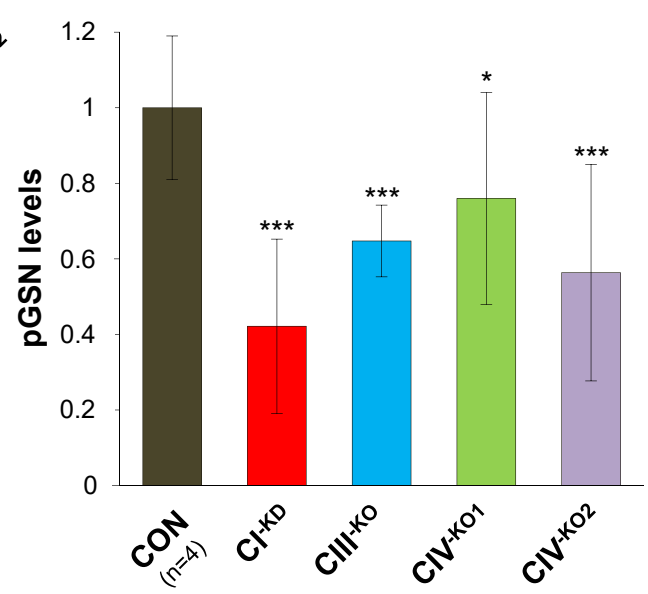

Figure 2. Relative expression of gelsolin isoforms in mitochondrial and secreted protein extracts from mutant transmitochondrial cybrids. (A) In total, $15 \mu \mathrm{g}$ of protein extracts from control (CON) and transmitochondrial mutant cybrids $\left(\mathrm{CI}^{-\mathrm{KD}}, \mathrm{CIII}{ }^{-\mathrm{KO}}, \mathrm{CIV} 1^{-\mathrm{KO}}\right.$, and $\left.\mathrm{CIV} 2^{-\mathrm{KO}}\right)$ were separated on $10 \%$ SDS-PAGE gels. GSN levels were analyzed by immunoblotting in whole-cell lysates and isolated mitochondria, using $\beta$-actin as the loading control for the whole-cell lysates, and SDHA for the mitochondrial fractions. The signals from four independent experiments per fraction were quantified, normalized by their respective loading controls, and data are presented as the mean \pm SD relative to control values, set as 1. GSN, cytosolic GSN; mGSN, mitochondrial GSN. (B) In total, $10 \mu \mathrm{g}$ of protein extracts from whole-cell lysates (WCLs) and mitochondrial fractions (MFs), as well as $35 \mu \mathrm{g}$ of protein extracts from secreted fractions or secretomes (Ss), were separated by 6\% SDS-PAGE. GSN isoforms were analyzed by Western blot. GSN, cytosolic GSN; pGSN, plasma GSN. (C) In total, $30 \mu \mathrm{g}$ of secreted protein extracts were separated on $4-20 \%$ TGX ${ }^{\mathrm{TM}}$ Precast Protein Gels (Biorad) and pGSN levels were analyzed by immunoblotting. The signals from six independent experiments were quantified, normalized by the total protein amount per lane, and data are presented as the mean \pm SD relative to control values, set as 1 . Mann-Whitney $U$ test: ${ }^{*} p<0.05 ;{ }^{* * *} p<0.001$. 
Table 3. Relative levels of mGSN and pGSN in human cultured cells.

\begin{tabular}{|c|c|c|c|c|}
\hline Cell Type & Sample & mGSN & pGSN & mGSN/pGSN \\
\hline \multirow{7}{*}{ Mutant Cybrids } & $\mathrm{CON}$ & $1 \pm 0.40$ & $1 \pm 0.20$ & 1 \\
\hline & $\mathrm{CI}^{-\mathrm{KD}}$ & $4.66 \pm 0.29 * * *$ & $0.42 \pm 0.23^{* * *}$ & 11.10 \\
\hline & $\mathrm{CIII}^{-\mathrm{KO}}$ & $3.70 \pm 0.54^{* * *}$ & $0.65 \pm 0.09 * * *$ & 5.69 \\
\hline & $\mathrm{CIV}^{-\mathrm{KO} 1}$ & $5.11 \pm 0.98^{* * *}$ & $0.76 \pm 0.28 *$ & 6.72 \\
\hline & $\mathrm{CIV}^{-\mathrm{KO} 2}$ & $3.78 \pm 1.44^{* * *}$ & $0.56 \pm 0.29^{* * *}$ & 6.75 \\
\hline & $\mathrm{CON}$ & $1 \pm 0.25$ & $1 \pm 0.07$ & 1 \\
\hline & P1 & $2.40 \pm 1.00$ & $0.25 \pm 0.08$ & 9.60 \\
\hline BCSL1 Mutant & P2 & $2.27 \pm 0.31$ & $0.27 \pm 0.17$ & 8.41 \\
\hline \multirow[t]{4}{*}{ Fibroblasts II } & P3 & $2.60 \pm 0.94$ & $0.20 \pm 0.09$ & 13.00 \\
\hline & P4 & $2.23 \pm 0.64$ & $0.51 \pm 0.15$ & 4.37 \\
\hline & $\mathrm{CON}$ & $1 \pm 0.25$ & $1 \pm 0.33$ & 1 \\
\hline & $2 \mathrm{nM}$ AA & $1.07 \pm 0.25$ & $0.81 \pm 0.27$ & 1.32 \\
\hline AA-treated & $20 \mathrm{nM}$ AA & $1.16 \pm 0.33$ & $0.76 \pm 0.38$ & 1.53 \\
\hline \multirow[t]{2}{*}{ Fibroblasts II } & 200 nM AA & $1.35 \pm 0.35 *$ & $0.67 \pm 0.26 *$ & 2.02 \\
\hline & 500 nM AA & $1.39 \pm 0.34^{* * *}$ & $0.34 \pm 0.16^{*}$ & 4.09 \\
\hline \multirow{3}{*}{$\begin{array}{l}\text { HEK 293T } \\
\quad \text { Cells }\end{array}$} & $\mathrm{CON}$ & $1 \pm 0.17$ & $1 \pm 0.27$ & 1 \\
\hline & $\mathrm{COX} 18^{-\mathrm{KO}}$ & $1.32 \pm 0.06$ & $0.76 \pm 0.13$ & 1.75 \\
\hline & $\mathrm{COX} 18^{-\mathrm{KO}+\mathrm{COX} 18}$ & $1.18 \pm 0.15$ & $1.01 \pm 0.20$ & 1.16 \\
\hline
\end{tabular}

Relationship between mGSN and pGSN levels quantified in transmitochondrial mutant cybrids, complex III-deficient fibroblasts with mutations in BCS1L, antimycin A (AA)-treated control fibroblasts, and genetically modified HEK293T cells. II The relative mGSN levels were calculated in reference [39]. Numerical values represent the mean \pm SD to the mean control (CON) value (set as 1 ) of four independent experiments. Mann-Whitney $U$ test: ${ }^{*} p<0.05$; *** $p<0.001$.

\subsection{Plasma GSN Levels Are Significantly Reduced in the Secretomes from Human Cybrids with OXPHOS Deficiency}

Next, we examined the levels of the secreted plasma GSN isoform (pGSN) in extracellular media protein extracts (secretomes) from control and mutant cybrids with OXPHOS deficiency. To confirm this, we identified the specific pGSN isoform in the secretomes from cultured cells, rather than the possible non-specific release of cytosolic GSN in the extracellular media by damaged cells. We first performed a Western blot analysis with an antibody that recognizes both isoforms in whole-cell lysates, mitochondrial fractions, and secretomes from cybrids lacking complex III and an isogenic control (Figure 2B). As expected, the band corresponding to cytosolic GSN ( $81 \mathrm{kDa})$ was predominantly present in the cellular and mitochondrial lysates, and it displayed a slightly lower electrophoretic mobility relative to the pGSN isoform ( $\sim 86 \mathrm{kDa})$ observed in the cellular secretomes, compatible with their predicted molecular weights (https://www.uniprot.org/uniprot/P06396). Then, we compared pGSN levels in the secretomes from control and mutant cybrids (Figure 2C) by SDS-PAGE on TGX stain-free ${ }^{\mathrm{TM}}$ precast gels (Biorad), followed by Western blot and densitometric analyses of the pGSN signals. The total amount of protein on each lane was used as a loading control for the normalization of pGSN levels, and was calculated by the quantification of fluorescent signals derived from protein tryptophans that react with specific gel trihalo compounds upon UV radiation. Data from six independent experiments revealed a significant decrease of pGSN levels in the secretomes from all mutant cybrids compared to their isogenic controls (Table 3).

\subsection{Plasma GSN Levels Are Significantly Reduced in Primary Fibroblast Cultures with OXPHOS Deficiency}

To exclude that these effects were specific to cybrid cell lines, we tested pGSN levels in the secretomes from primary cultured fibroblasts from patients harboring pathogenic mutations in the complex III assembly factor BCS1L (Figure 3A), which previously showed a marked respiratory 
chain dysfunction [12] together with an upregulated expression and mitochondrial location of GSN (Table 3) [40]. SDS-PAGE gels were stained with Coomassie blue and densitometric measurements per lane were used as loading controls for the normalization of subsequent pGSN immunoreactive signals. Results from two independent experiments revealed a clear trend towards a decrease in pGSN levels in the secretomes from BCS1L mutant fibroblasts compared to controls (Figure 3A).

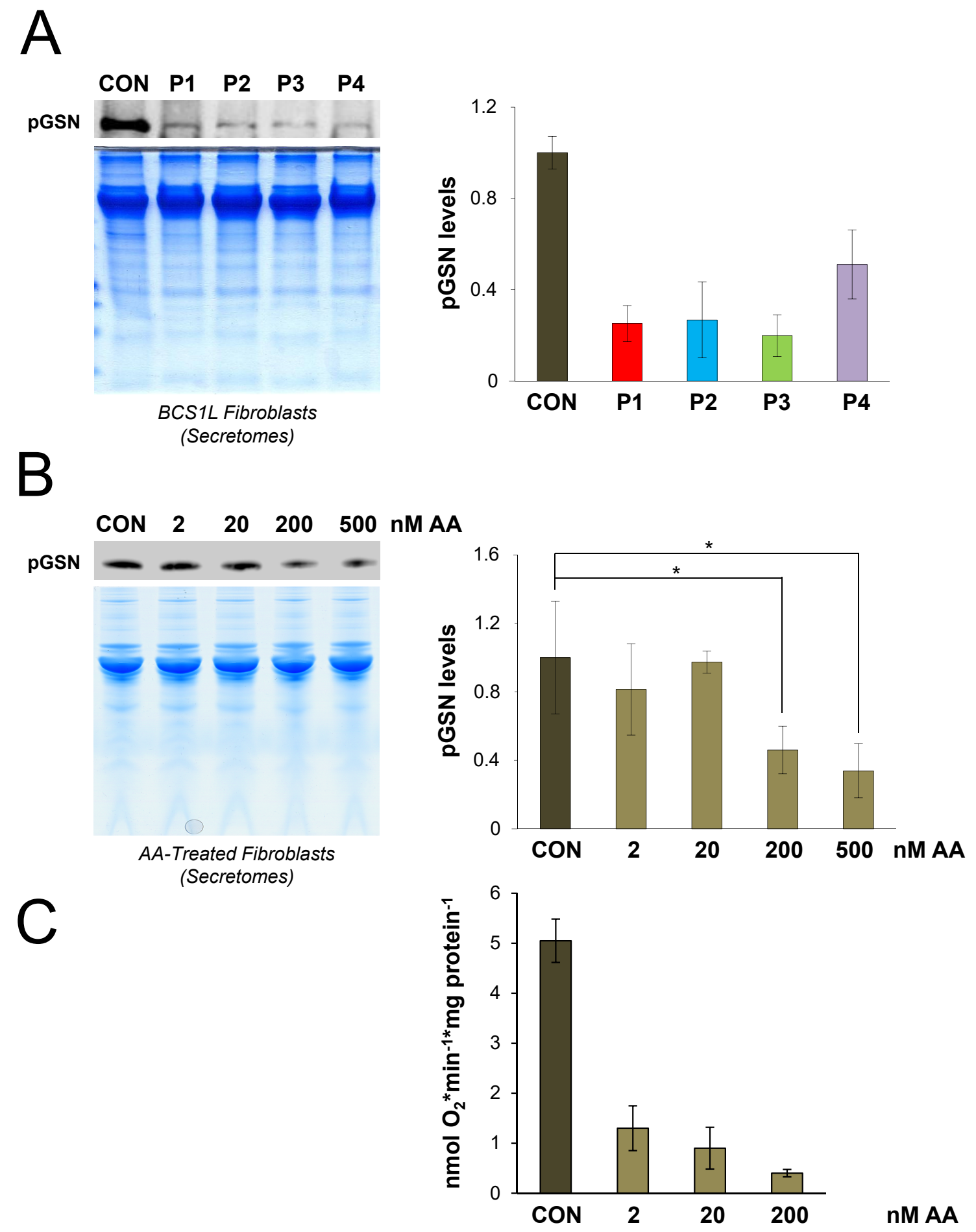

Figure 3. Plasma gelsolin levels are decreased in human fibroblasts with respiratory chain deficiency. (A) In total, $25 \mu \mathrm{g}$ of secreted protein extracts from control (CON) and mutant fibroblasts from patients (P1-P4) harboring pathogenic mutations in the assembly factor BCS1L were separated on 10\% SDS-PAGE 
gels, and pGSN levels were analyzed by immunoblotting. Duplicate gels were stained with Coomassie blue to serve as the loading control (bottom image). The signals from two independent experiments were quantified, normalized by the total protein amount per lane in the Coomassie-stained gels, and data are presented as the mean \pm SD relative to control values, set as 1 . (B) Control fibroblasts were cultured for $48 \mathrm{~h}$ in the presence of 2, 20, 200, and $500 \mathrm{nM}$ of antimycin A (AA). In total, $25 \mu \mathrm{g}$ of secreted protein extracts were separated on 10\% SDS-PAGE gels and pGSN levels were subsequently analyzed by Western blot. The signals from four independent experiments were quantified, normalized by the total protein amount per lane, and data are presented as the mean \pm SD relative to the control values, set as 1. Mann-Whitney $U$ test: ${ }^{*} p<0.05$. (C) Mitochondrial basal oxygen consumption rates (OCR) were analyzed in antimycin A (AA)-treated control fibroblasts respiring in $1 \mathrm{~g} / \mathrm{L}$ glucose-containing medium. Four technical replicates per sample were measured and data are expressed as the mean \pm SD of the untreated cells $(\mathrm{CON})$ values. OCR values were calculated in $\mathrm{pmol} \mathrm{O}_{2} \cdot \mathrm{min}^{-1} \cdot \mu \mathrm{g}$ protein ${ }^{-1}$ in all experiments.

To analyze whether functional rather than structural defects of the OXPHOS system underlie these variations in pGSN levels, we extended our analysis to control fibroblasts treated for $48 \mathrm{~h}$ with increasing concentrations (ranging between 2 and $500 \mathrm{nM}$ ) of the complex III inhibitor antimycin A (Table 3), which does not affect the assembly or stability of the OXPHOS complexes [40]. Data from four independent experiments showed a significant decrease in pGSN levels only at concentrations of 200 and $500 \mathrm{nM}$ of antimycin A (Figure 3B), which correlated with the decreasing mitochondrial oxygen consumption rates that were below $10 \%$ of the mean control value at the highest doses ( $\geq 200 \mathrm{nM})$ of the inhibitor (Figure 3C). Importantly, we previously observed a significant increase of mGSN levels at these two highest inhibitor concentrations [40] (Table 3), again suggesting an inverse correlation between mGSN and pGSN levels in cells with OXPHOS deficiency.

\subsection{Increased Mitochondrial-to-Plasma GSN Ratio in Human Cellular Models of OXPHOS Deficiency}

Altogether, our data indicate that the enrichment of mGSN takes place in parallel to a decreased secretion of the pGSN isoform, and both events seem to arise as a combined response to an enzymatic dysfunction of the OXPHOS system. To establish a numerical correlation that integrates the experimental observations in our different cellular models of OXPHOS deficiency, we calculated the mGSN-to-pGSN protein ratios (Table 3). In mutant cybrids with structural and functional alterations of the MRC complexes, the mGSN:pGSN ratios ranged between $\sim 6$ - and 11-fold higher than the values measured in their isogenic controls. In fibroblasts with mutations in BCS1L, the mGSN:pGSN ratios oscillated between $\sim 4$ and 13 times higher than the control values. Additionally, in antimycin A-treated control fibroblasts, the mGSN:pGSN ratios increased gradually in a dose-dependent manner from $~ 1.3-$ to 4 -fold relative to the untreated cells. Overall, these data indicate that the mGSN-to-pGSN protein ratio is consistently increased in cultured cell lines with a defective respiratory chain, suggesting that it constitutes a bona fide hallmark of OXPHOS dysfunction.

\subsection{The Mitochondrial-to-Plasma GSN Ratio Can Be Modulated by Genetic Manipulation of OXPHOS-Deficient Cell Lines}

Next, we checked whether the mGSN:pGSN ratio was reversibly modulated in response to the genetic manipulation of human HEK293T cells depleted of COX18 (COX18-KO), an assembly factor essential for the biogenesis and function of complex IV [47]. We observed a clear upregulation of mGSN levels in purified mitochondria from COX18-KO cells (Figure 4A), in parallel with decreased pGSN levels in the secretomes (Figure 4B). As a result, the mGSN:pGSN ratio was nearly 2-fold higher in COX18-KO cells than the wild-type control (Table 1). These effects were reversed by stable overexpression of COX18-KO (COX18-KO ${ }^{+\mathrm{COX} 18}$ cells) (Figure 4C), which recovered the mGSN:pGSN ratio to normal values (Table 3). Therefore, the mGSN:pGSN ratio may change in response to the genetic manipulation of OXPHOS-deficient cell lines. 

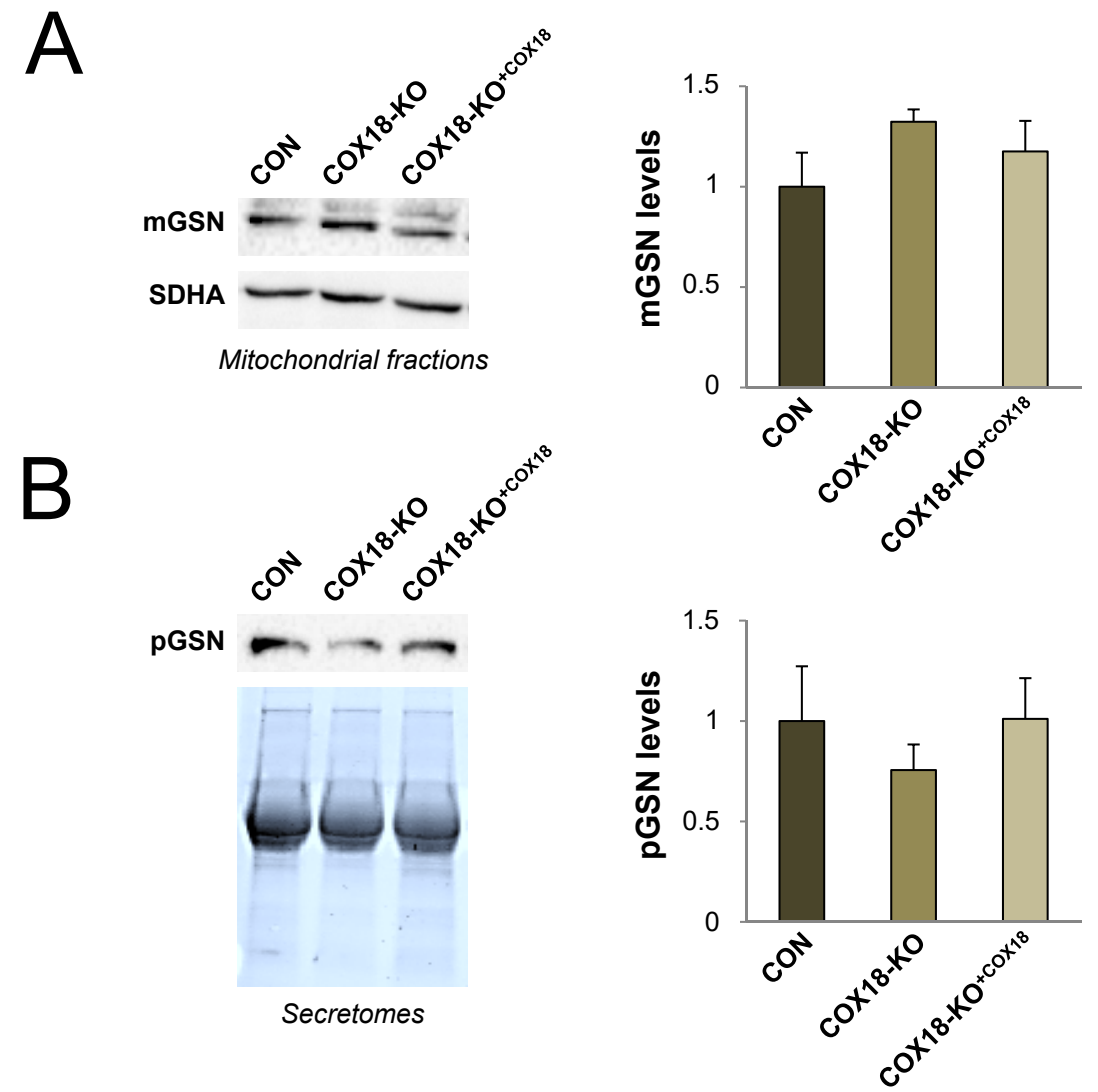

Figure 4. Modulation of the mGSN:pGSN ratio by genetic manipulation of OXPHOS deficiency. Control HEK293T cells (CON, $\mathrm{n}=3)$, and mutant cells depleted of COX18 (COX18-KO, n = 2) and subsequently rescued by stable overexpression of wild-type COX18 $\left(\mathrm{COX} 18-\mathrm{KO}^{+\mathrm{COX} 18}, \mathrm{n}=3\right)$ were harvested at $90 \%$ confluence. (A) In total, $40 \mu \mathrm{g}$ of mitochondrial protein extracts were separated on $10 \%$ SDS-PAGE gels. mGSN levels were analyzed by immunoblotting, using SDHA as the loading control. (B) In total, $50 \mu \mathrm{g}$ of secreted protein extracts were separated on 4-20\% TGXTM Precast Protein Gels (Biorad). pGSN levels were analyzed by immunoblotting and normalized by the total protein amount per lane. Experimental data are presented as the mean \pm SD relative to control values, set as 1 . mGSN, mitochondrial GSN; pGSN, plasma GSN.

3.6. Oxidative Stress Does Not Trigger the Upregulation and Mitochondrial Location of Cytoplasmic Gelsolin in Human Cybrids

We next analyzed whether the observed upregulation and mitochondrial localization of cytosolic GSN was a general phenomenon occurring as a response to any type of oxidative stress, rather than being specific to OXPHOS dysfunction. We first examined the intracellular redox state in control and mutant cybrids with OXPHOS deficiency by measuring endogenous hydrogen peroxide $\left(\mathrm{H}_{2} \mathrm{O}_{2}\right)$ levels (Figure 5A). Despite the severity of the enzymatic defects in all mutants, the measurements showed significantly increased $\mathrm{H}_{2} \mathrm{O}_{2}$ levels only in the CIII-KO and CIV-KO2 cybrids relative to the controls. In contrast, $\mathrm{H}_{2} \mathrm{O}_{2}$ levels remained within the normal range in the CI-KD and CIV1-KO cybrids, harboring pathogenic homoplasmic mutations in the MT-ND2 and MT-CO1 genes, respectively, in agreement with previous observations $[53,54]$. These results exclude a straightforward correlation between the increased mGSN levels and the varying endogenous $\mathrm{H}_{2} \mathrm{O}_{2}$ levels in the analyzed cell lines.

We next tested whether mGSN expression was upregulated by oxidative stress in a concentration-dependent manner in control 143B- $\mathrm{TK}^{-}$cells treated with increasing concentrations of exogenous $\mathrm{H}_{2} \mathrm{O}_{2}(100,200$, and $500 \mu \mathrm{M})$ for 6, 24, and $36 \mathrm{~h}$ (Figure $5 \mathrm{~B}$ ), as previously shown in HEK293T cells [36]. $\mathrm{H}_{2} \mathrm{O}_{2}$ treatment did not alter GSN steady-state levels in the whole cell lysates but surprisingly led to a significant decrease of mGSN levels in the mitochondrial fractions. 
A

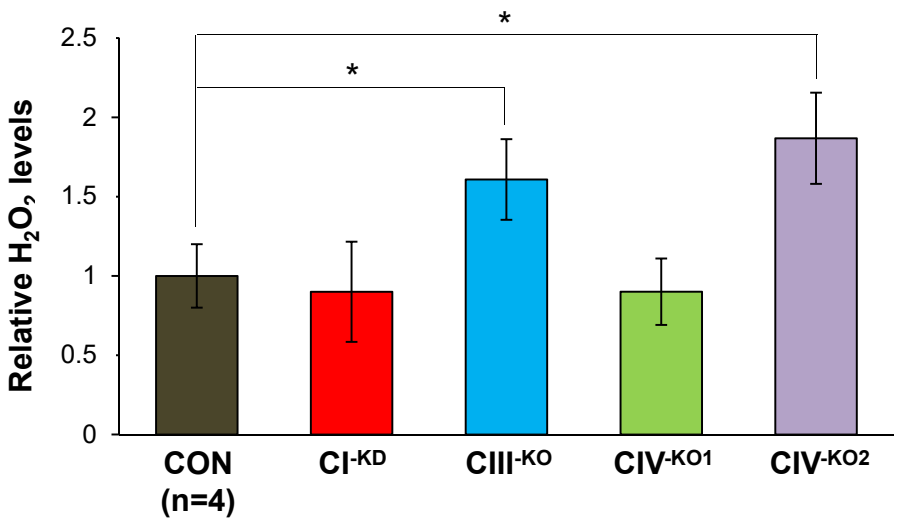

B
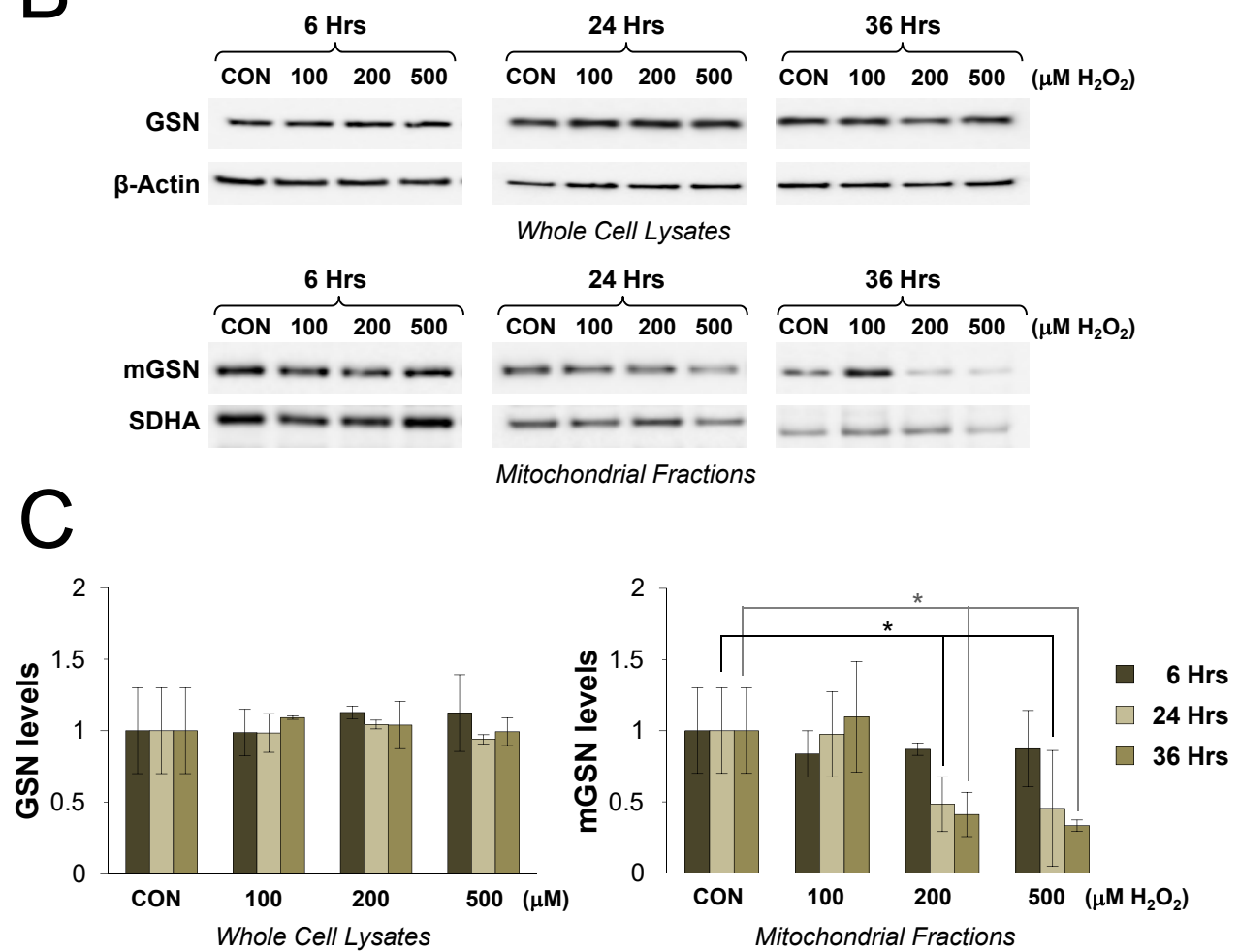

Figure 5. Oxidative stress does not trigger the upregulation and mitochondrial location of gelsolin. (A) Hydrogen peroxide levels in isogenic controls $(\mathrm{CON}, \mathrm{n}=4)$ and transmitochondrial mutant cybrids $\left(\mathrm{CI}^{-\mathrm{KD}}, \mathrm{CIII}{ }^{-\mathrm{KO}}, \mathrm{CIV}^{-\mathrm{KO}}\right.$, and $\left.\mathrm{CIV} 2^{-\mathrm{KO}}\right)$. Values from eight independent experiments per cell line were normalized by the total protein amount per sample. Data are presented as the mean $\pm \mathrm{SD}$ of each mutant cell line relative to the mean values of the four isogenic controls, set as 1 . Mann-Whitney $U$ test: $* p<0.05$. (B) Control cybrids were cultured for 6,24 , and $36 \mathrm{~h}$ in the presence of 100, 200, and $500 \mu \mathrm{M}$ of hydrogen peroxide $\left(\mathrm{H}_{2} \mathrm{O}_{2}\right)$. In total, $15 \mu \mathrm{g}$ of whole-cell and mitochondrial protein extracts were separated on $10 \%$ SDS-PAGE gels and GSN levels were subsequently analyzed by Western blot, using $\beta$-actin as the loading control for the whole-cell lysates, and SDHA for the mitochondrial fractions. (C) The signals from four independent experiments were quantified and normalized by their respective loading controls. Data are presented as the mean \pm SD relative to the untreated cells $(\mathrm{CON})$ values, set as 1 . Mann-Whitney $U$ test: ${ }^{*} p<0.05$. GSN, cytosolic GSN; mGSN, mitochondrial GSN.

Similarly, control cells were treated with 1 and $2 \mu \mathrm{M}$ of the cell death inductor staurosporine (STS) for 6 to $24 \mathrm{~h}$ (Figure 6A). Under these conditions, we also observed a significant decrease in mGSN levels (Figure 6B,C) that correlated with cell death (Figure 6A). These data support the notion that $\mathrm{H}_{2} \mathrm{O}_{2}$ 
treatment may induce protein degradation as a consequence of cell death activation, as previously described [55], and exclude that the upregulation and mitochondrial location of cytosolic GSN primarily responds to alterations in intracellular ROS.
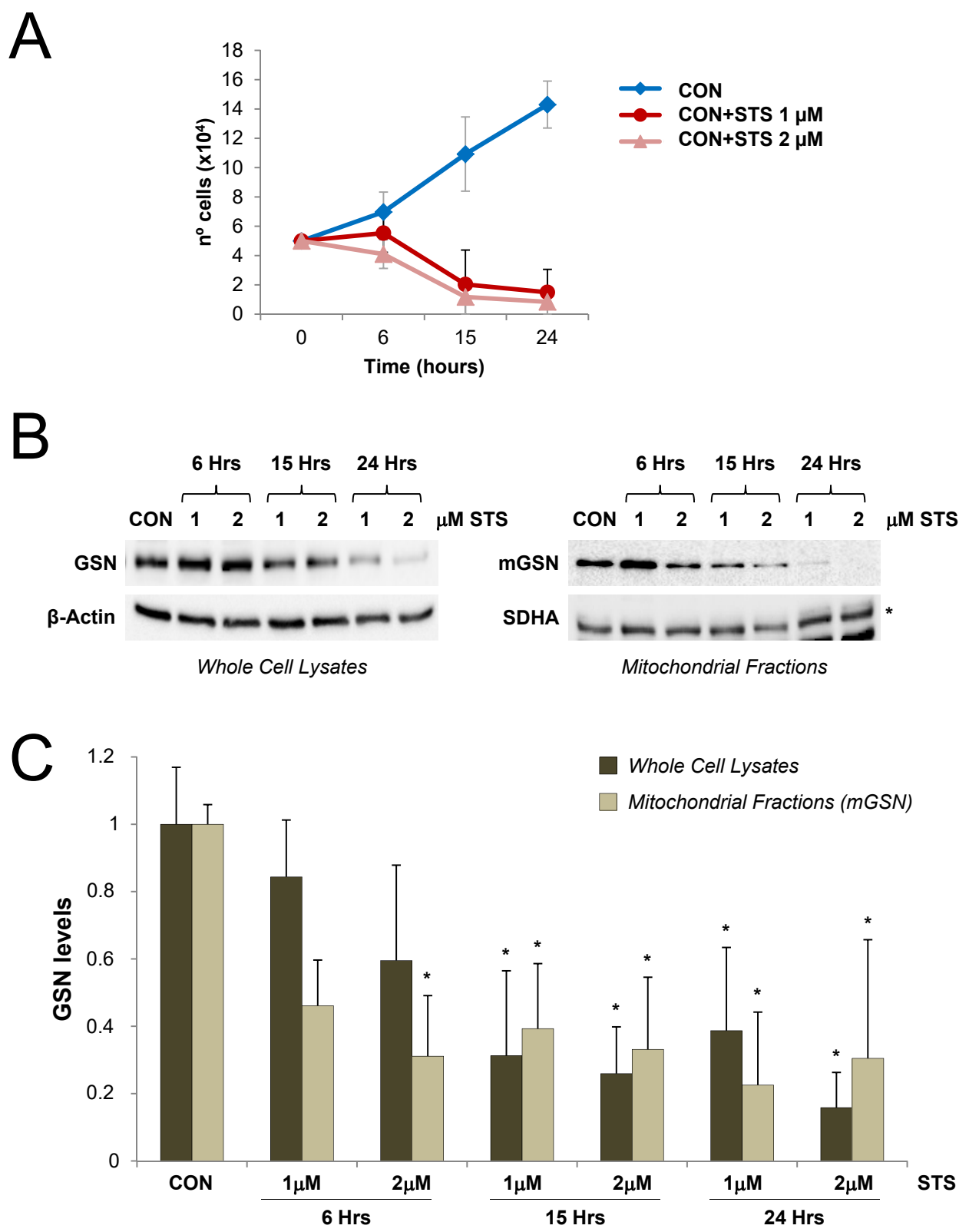

Figure 6. Gelsolin levels decrease upon cell death induction. Control cybrids were cultured for 6, 15, and $24 \mathrm{~h}$ in the presence of $1-2 \mu \mathrm{M}$ of staurosporine (STS). (A) Cell death rates upon STS treatment. Here, $5 \times 10^{4}$ cells were seeded in 6-well plates and data are presented as the mean \pm SD of three experimental replicates per condition. (B) In total, $15 \mu \mathrm{g}$ of whole-cell and mitochondrial protein extracts were separated on 10\% SDS-PAGE gels and GSN levels were subsequently analyzed by Western blot, using $\beta$-actin as the loading control for the whole-cell lysates, and SDHA for the mitochondrial fractions (indicated with an asterisk). (C) The signals from four independent experiments were quantified and normalized by their respective loading controls. Data are presented as the mean $\pm \mathrm{SD}$ relative to the untreated cells (CON) values, set as 1. Mann-Whitney $U$ test: * $p<0.05$. GSN, cytosolic GSN; mGSN, mitochondrial GSN. 
3.7. Mitochondrial-to-Plasma GSN Ratio Increases in Blood Samples from Patients with Mitochondrial OXPHOS Disease

Finally, we aimed to determine if a high mGSN:pGSN ratio could be potentially used as a future diagnostic biomarker for OXPHOS dysfunction, by initially comparing blood samples from nine adult patients with mitochondrial OXPHOS disorders (Table 1) relative to nine sex- and age-matched healthy individuals, used as controls (Table 2).

To calculate cytosolic GSN levels, we used Western blot followed by GSN immunodetection in whole-cell protein extracts, in cytosolic and in mitochondrial fractions from isolated peripheral blood mononuclear cells (PBMCs), using $\beta$-actin and SDHA as loading controls (Figure 7A). Normalized densitometric values revealed significantly increased amounts of $\mathrm{mGSN}$ in the mitochondrial fractions, while no significant differences in GSN levels were detected in the remaining PBMC fractions between mitochondrial disease (MD) patients and healthy controls. Interestingly, the mean mGSN value was 2.5-fold higher in the MD patients than in the healthy individuals (Figure 7A, right graph). To calculate pGSN levels, we used ELISA assays to measure the pGSN levels in plasma samples from the same MD patients. Comparison of the relative pGSN values in MD patients (Table 1) and healthy controls (Table 2) revealed a slight, yet not significant, decrease of pGSN levels in the MD patients when the mean control value was set as 1 (Figure 7B). Based on these results, the average mGSN:pGSN ratio was significantly higher (ranging between 2.5- and 5-fold) in the MD patients than in controls, with this ratio being well above all control values in four patients (Figure 7C). Unlike our previous observations in the cellular models, mGSN upregulation in PBMCs did not always correlate with a decline of blood pGSN levels in every MD patient (Table 1). These differences probably rise from the wide genetic heterogeneity between the individual healthy donors and patients' samples, where all individuals are genetically diverse, versus the relative genetic homogeneity of the established cell lines, which allows the establishment of direct comparisons between controls and mutant cells. Therefore, our results, though promising, require further studies to establish the real diagnostic value of the mGSN-to-pGSN protein ratio in blood samples from larger cohorts of healthy controls and patients with mitochondrial OXPHOS disease, as well as of patients with unrelated pathologies. 
A

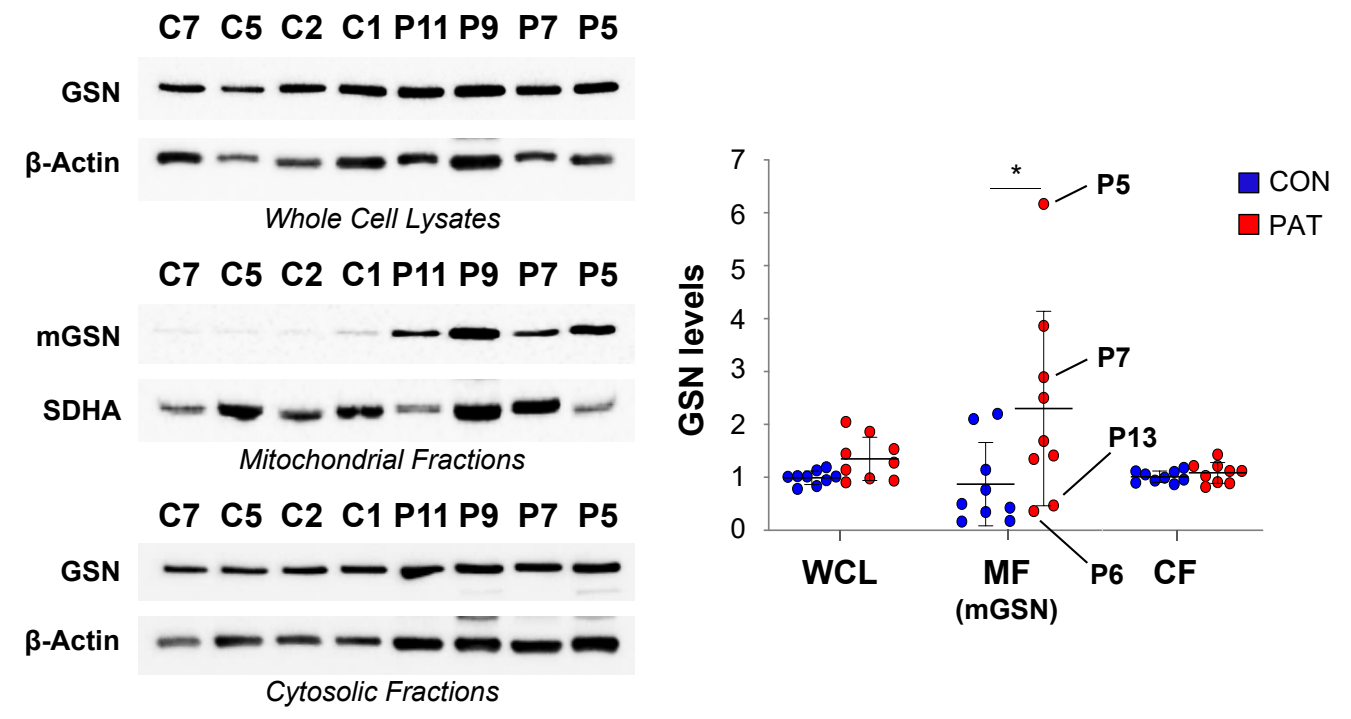

B
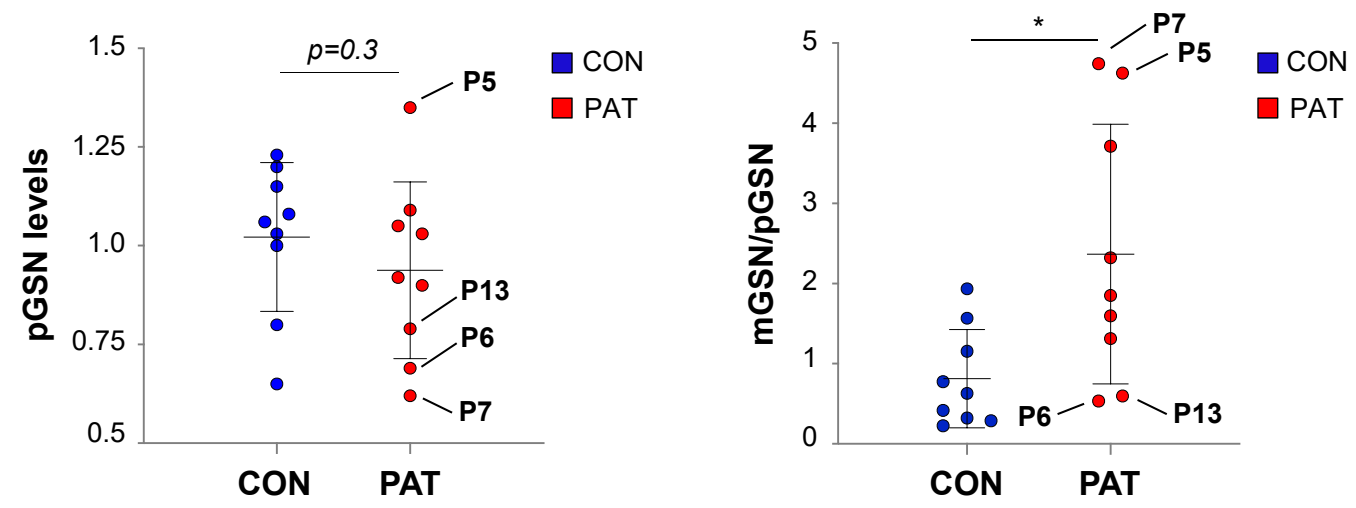

Figure 7. Relative mGSN and pGSN levels in blood samples from patients with mitochondrial OXPHOS disease (MD). (A) In total, $15 \mu \mathrm{g}$ of protein extracts from whole-cell lysate, mitochondrial, and cytosolic fractions from PBMCs isolated from healthy controls (C1-C9, CON) and MD patients (P5-P13, PAT) were separated on $10 \%$ SDS-PAGE gels. GSN levels were analyzed by immunoblotting, using $\beta$-actin and SDHA as loading controls. (Graph) The signals from three independent biological replicates per fraction were quantified and normalized by their respective loading controls. Each data point represents an individual subject and overall data are presented as the mean \pm SD relative to the mean control value. (B) Relative pGSN levels from the blood samples of healthy controls (CON) and MD patients (PAT) were determined by ELISA. Each data point represents an individual subject, and overall data are indicated as the mean \pm SD from four measurements relative to the mean control value. (C) Calculation of the mGSN:pGSN ratios in blood from healthy controls and MD patients. Each data point represents an individual subject, and overall data are indicated as the mean $\pm \mathrm{SD}$, relative to the mean control value. The four patients with the most extreme mGSN:pGSN ratios (P5, P6, P7, P13) are indicated. For (A-C), Mann-Whitney $U$ test: ${ }^{*} p<0.05$. GSN, cytosolic GSN; mGSN, mitochondrial GSN; pGSN, plasma GSN.

\section{Discussion}

In this work, we identified a high mGSN-to-pGSN protein ratio as a novel hallmark of OXPHOS dysfunction in human cultured cells. Our data demonstrate that: (1) The cytoplasmic GSN isoform levels are significantly upregulated in the mitochondria from primary fibroblasts and transmitochondrial 
cybrid cell lines with MRC enzyme deficiency. (2) In parallel, the secreted pGSN isoform levels are significantly decreased in the extracellular environment from human cells with MRC deficiency. (3) The mGSN-to-pGSN ratio values can be modulated by genetic modification of OXPHOS-deficient cell lines. (4) This physiological reverse correlation between both GSN isoforms has not been previously reported in other pathologies. Therefore, we propose to use the ratio between mitochondrial GSN (mGSN) and pGSN levels in the extracellular medium as an indicator of the pathophysiological response to MRC deficiency in cultured cells. This can be extremely helpful, for instance, to differentiate the impact of specific pathogenic mutations or drug treatments in different cultured cell types originally derived from patients, as well as to select for genetically edited cellular models of mitochondrial disorders (MDs). (5) In addition, we provide a proof of principle for future research on the mGSN:pGSN ratio as a potential diagnostics tool for MDs. Since pGSN levels can be easily assessed in blood from patients with unrelated pathologies and healthy individuals [28,56-60], our analyses could be hypothetically extrapolated from cellular models to plasma samples from large cohorts of healthy individuals, as well as of patients with both MDs and unrelated disorders.

Previous 2-D-DIGE proteomics approaches on primary cultured fibroblasts with mutations in the MRC complex III assembly factor BCS1L revealed a significant overexpression of the actin-binding protein GSN in response to complex III deficiency [12]. We next showed that upregulated GSN was primarily located in the mitochondrial fractions from several cellular models with complex III enzymatic or structural defects, where it binds the VDAC pore in the outer mitochondrial membrane to promote antiapoptotic responses [40]. Now, we showed that the increased mGSN levels occur in parallel to a significant decrease in the levels of the secreted pGSN isoform, and that this mechanism is a general response to OXPHOS deficiency with no significant differences among the mitochondrial complexes affected.

In our cellular models, either genetic or enzymatic alterations of the OXPHOS system triggered at least nearly a $\sim 2$-fold increase in the mGSN:pGSN ratio values when compared to control cells without MRC impairment, suggesting that mGSN:pGSN ratio values $\geq 2$ would correlate with a poor functioning of the MRC in human cultured cells. However, large differences in the mGSN:pGSN ratio values were observed between mutant fibroblasts, cybrids, and HEK293T cells, which could arise from their different genetic backgrounds and metabolic requirements for ATP synthesis. In highly proliferating cells, like osteosarcoma-derived cybrids or embryonic HEK293T cells, glycolysis accounts for $20-90 \%$ of total ATP production, depending on the cell type, with the remainder contributed by mitochondrial oxidation of pyruvate, fatty acids, and glutamine. In contrast, differentiated cells may produce about $95 \%$ of the total ATP by OXPHOS and the remaining 5\% through aerobic glycolysis [61], which could be the main reason for the largest mGSN:pGSN ratio values in fibroblasts. In addition to their diverse glycolytic capacity, HEK293T cells expressed much lower levels of endogenous GSN than cybrids and fibroblasts, which could also contribute to the differences in the mGSN:pGSN ratio values among these cell types.

Our results suggest that OXPHOS enzymatic dysfunction by itself could be the primary mechanism modulating the expression and localization of both GSN isoforms. These observations, however, do not exclude that the increased mGSN-to-pGSN protein ratios could be a consequence of secondary metabolic or physiopathological alterations induced by MRC enzymatic defects. Among these physiopathological alterations, we considered raised ROS levels to be a likely cause eliciting high mGSN-to-pGSN protein ratios, since oxidative stress was previously reported to increase the expression of cytoplasmic GSN [36]. However, our data do not support this hypothesis for the following reasons: (a) Not all the tested cell lines showed elevated endogenous $\mathrm{H}_{2} \mathrm{O}_{2}$ levels, despite a severe MRC defect associated with a significant upregulation of the mGSN-to-pGSN protein ratios. For instance, the mutant cybrids depleted of MT-CYB [42,62] and MT-CO2 [51] showed increased $\mathrm{H}_{2} \mathrm{O}_{2}$ levels. Similarly, most primary fibroblasts with mutations in $B C S 1 L$ were previously shown to display increased ROS by measuring the amount of oxidized DCFDA to DCF [11]. However, fibroblasts from one patient with the pathogenic p.T50A substitution in BCS1L [11,63] (P4 in our current study) showed normal endogenous $\mathrm{H}_{2} \mathrm{O}_{2}$ levels. In our 
study, mutant cybrids depleted of MT-ND2 [41] and of MT-CO1 [44] also displayed normal $\mathrm{H}_{2} \mathrm{O}_{2}$ levels, in agreement with previous observations [53]. (b) Control 143B-TK ${ }^{-}$cells treated with increasing $\mathrm{H}_{2} \mathrm{O}_{2}$ concentrations for up to $36 \mathrm{~h}$ actually displayed a significant decrease, rather than an increase, of mGSN levels, more compatible with a general protein degradation as a consequence of cell death activation, as previously described [55]. Similar results were obtained in staurosporine-treated cells, thus excluding a direct correlation between the upregulation of mGSN levels, variations in intracellular ROS levels, and apoptotic cell death. However, we cannot disregard other possible secondary consequences of MRC dysfunction as potential causes of increased mGSN:pGSN protein ratios, including alterations in the mitochondrial membrane potential and ATP synthesis rates [64], or altered oscillations of the intramitochondrial calcium flux [65]. In this regard, it seems especially relevant to gain insight into the interplay between calcium homeostasis and the upregulation of mGSN, as the activity of this protein is regulated by cytosolic calcium [15], and cytosolic GSN expression was shown to be upregulated in human cell lines by treatment with calcium ionophores [35]. In conclusion, our data demonstrate that a high mGSN:pGSN protein ratio is a general response to OXPHOS dysfunction in human cultured cells, but the precise underlying mechanism triggering these cellular adaptations remains open to question.

Author Contributions: Conceptualization, C.U.; Data curation, C.U., A.G.-B., A.P., M.I., V.B., S.L.-C., R.P.-P. and L.M.-B.; Formal analysis, C.U., A.G.-B., A.P., M.I., V.B., S.L.-C., R.P.-P., and L.M.-B.; Funding acquisition, C.U. and M.A.M.; Investigation, C.U., A.G.-B., A.P., M.I., V.B., S.L.-C., R.P.-P. and L.M.-B.; Methodology, C.U., A.G.-B., A.P., M.I., V.B. and M.A.M.; Project administration, J.A.; Resources, C.U., Cristina Domínguez-González, J.A. and M.A.M.; Software, A.P.; Supervision, C.U.; Validation, C.U., A.G.-B., A.P. and M.I.; Visualization, C.U., A.G.-B. and A.P.; Writing—original draft, C.U.; Writing—review and editing, A.G.-B., A.P., M.I., V.B., S.L.-C., R.P.-P., L.M.-B., C.D.-G., J.A. and M.A.M. All authors have read and agreed to the published version of the manuscript.

Funding: Research was supported by Instituto de Salud Carlos III-MINECO/European FEDER Funds grants PI17-00048 (to CU) and PI18-01374 (to MAM), and by Comunidad Autónoma de Madrid/ERDF-ESF grant P2018/BAA-4403 (to CU).

Acknowledgments: Authors acknowledge A. Romero-Cea for technical assistance; S. Seneca (Center for Medical Genetics, Brussels, Belgium), M.T. García-Silva (Hospital 12 de Octubre, Madrid, Spain), M. Vázquez López (Hospital General Universitario Gregorio Marañón, Madrid, Spain), and A. Verdú (Hospital Virgen de la Salud, Toledo, Spain) for kindly providing the patients' fibroblasts; and G. Manfredi (Weill Cornell Medical College Brain and Mind Research Institute, New York, USA), J.A. Enríquez (Centro Nacional de Investigaciones Cardiovasculares Carlos III, Madrid, Spain), C.T. Moraes and A. Barrientos (University of Miami Miller School of Medicine, Miami, USA) for kindly providing the mutant transmitochondrial cybrids and HEK293T cells.

Conflicts of Interest: The authors declare no competing interests.

\section{References}

1. Reid, R.A.; Moyle, J.; Mitchell, P. Synthesis of adenosine triphosphate by a protonmotive force in rat liver mitochondria. Nature 1966, 212, 257-258. [CrossRef] [PubMed]

2. McCormick, E.M.; Zolkipli-Cunningham, Z.; Falk, M.J. Mitochondrial disease genetics update. Curr. Opin. Pediatrics 2018, 30, 714-724. [CrossRef] [PubMed]

3. Koliaki, C.; Roden, M. Alterations of Mitochondrial Function and Insulin Sensitivity in Human Obesity and Diabetes Mellitus. Annu. Rev. Nutr. 2016, 36, 337-367. [CrossRef] [PubMed]

4. Gonzalez-Franquesa, A.; Patti, M.-E. Insulin Resistance and Mitochondrial Dysfunction. Adv. Exp. Med. and Biol. 2017, 982, 465-520.

5. Mulder, H. Transcribing $\beta$-cell mitochondria in health and disease. Mol. Metab. 2017, 6, 1040-1051. [CrossRef]

6. Kawamata, H.; Manfredi, G. Proteinopathies and OXPHOS dysfunction in neurodegenerative diseases. J. Cell Biol. 2017, 216, 3917-3929. [CrossRef]

7. Area-Gomez, E.; Guardia-Laguarta, C.; Schon, E.A.; Przedborski, S. Mitochondria, OxPhos, and neurodegeneration: Cells are not just running out of gas. J. Clin. Investig. 2019, 129, 34-45. [CrossRef]

8. Sica, V.; Bravo-San Pedro, J.M.; Stoll, G.; Kroemer, G. Oxidative phosphorylation as a potential therapeutic target for cancer therapy. Int. J. Cancer 2019, 146, 10-17. [CrossRef]

9. Roth, K.G.; Mambetsariev, I.; Kulkarni, P.; Salgia, R. The Mitochondrion as an Emerging Therapeutic Target in Cancer. Trends Mol. Med. 2020, 26, 119-134. [CrossRef] 
10. Gorman, G.S.; Chinnery, P.F.; DiMauro, S.; Hirano, M.; Koga, Y.; McFarland, R.; Suomalainen, A.; Thorburn, D.R.; Zeviani, M.; Turnbull, D.M. Mitochondrial diseases. Nat. Rev. Dis. Primers 2016, 2, 1-22. [CrossRef]

11. Morán, M.; Marín-Buera, L.; Carmen Gil-Borlado, M.; Rivera, H.; Blázquez, A.; Seneca, S.; Vázquez-López, M.; Arenas, J.; Martín, M.A.; Ugalde, C. Cellular pathophysiological consequences of BCS1L mutations in mitochondrial complex III enzyme deficiency. Hum. Mutat. 2010, 31, 930-941. [CrossRef] [PubMed]

12. Marín-Buera, L.; García-Bartolomé, A.; Morán, M.; López-Bernardo, E.; Cadenas, S.; Hidalgo, B.; Sánchez, R.; Seneca, S.; Arenas, J.; Martín, M.A.; et al. Differential proteomic profiling unveils new molecular mechanisms associated with mitochondrial complex III deficiency. J. Proteom. 2015, 113, 38-56. [CrossRef] [PubMed]

13. Wagener, N.; Ackermann, M.; Funes, S.; Neupert, W. A Pathway of Protein Translocation in Mitochondria Mediated by the AAA-ATPase Bcs1. Mol. Cell 2011, 44, 191-202. [CrossRef] [PubMed]

14. Fernandez-Vizarra, E.; Bugiani, M.; Goffrini, P.; Carrara, F.; Farina, L.; Procopio, E.; Donati, A.; Uziel, G.; Ferrero, I.; Zeviani, M. Impaired complex III assembly associated with BCS1L gene mutations in isolated mitochondrial encephalopathy. Hum. Mol. Genet. 2007, 16, 1241-1252. [CrossRef] [PubMed]

15. Yin, H.L.; Stossel, T.P. Control of cytoplasmic actin gel-sol transformation by gelsolin, a calcium-dependent regulatory protein. Nature 1979, 281, 583-586. [CrossRef]

16. Li, G.H.; Arora, P.D.; Chen, Y.; McCulloch, C.A.; Liu, P. Multifunctional roles of gelsolin in health and diseases. Med. Res. Rev. 2012, 32, 999-1025. [CrossRef]

17. Feldt, J.; Schicht, M.; Garreis, F.; Welss, J.; Schneider, U.W.; Paulsen, F. Structure, regulation and related diseases of the actin-binding protein gelsolin. Expert Rev. Mol. Med. 2018, 20. [CrossRef]

18. Yin, H.L.; Kwiatkowski, D.J.; Mole, J.E.; Cole, F.S. Structure and biosynthesis of cytoplasmic and secreted variants of gelsolin. J. Biol. Chem. 1984, 259, 5271-5276.

19. Janmey, P.A.; Stossel, T.P. Gelsolin-polyphosphoinositide interaction. Full expression of gelsolin-inhibiting function by polyphosphoinositides in vesicular form and inactivation by dilution, aggregation, or masking of the inositol head group. J. Biol. Chem. 1989, 264, 4825-4831.

20. Kwiatkowski, D.J.; Stossel, T.P.; Orkin, S.H.; Mole, J.E.; Colten, H.R.; Yin, H.L. Plasma and cytoplasmic gelsolins are encoded by a single gene and contain a duplicated actin-binding domain. Nature 1986, 323, 455-458. [CrossRef]

21. Allen, P.G. Functional consequences of disulfide bond formation in gelsolin. FEBS Lett. 1997, 401, 89-94. [CrossRef]

22. Lind, S.E.; Smith, D.B.; Janmey, P.A.; Stossel, T.P. Role of plasma gelsolin and the vitamin D-binding protein in clearing actin from the circulation. J. Clin. Investig. 1986, 78, 736-742. [CrossRef] [PubMed]

23. Lee, W.M.; Galbraith, R.M.; Galbraith, R.M. The extracellular actin-scavenger system and actin toxicity. N. Engl. J. Med. 1992, 326, 1335-1341. [PubMed]

24. Piktel, E.; Levental, I.; Durnaś, B.; Janmey, P.; Bucki, R. Plasma Gelsolin: Indicator of Inflammation and Its Potential as a Diagnostic Tool and Therapeutic Target. Int. J. Mol. Sci. 2018, 19, 2516. [CrossRef]

25. Maury, C.P. Gelsolin-related amyloidosis. Identification of the amyloid protein in Finnish hereditary amyloidosis as a fragment of variant gelsolin. J. Clin. Investig. 1991, 87, 1195-1199. [CrossRef]

26. Solomon, J.P.; Page, L.J.; Balch, W.E.; Kelly, J.W. Gelsolin amyloidosis: Genetics, biochemistry, pathology and possible strategies for therapeutic intervention. Crit. Rev. Biochem. Mol. Biol. 2012, 47, 282-296. [CrossRef]

27. Khatri, N.; Sagar, A.; Peddada, N.; Choudhary, V.; Chopra, B.S.; Garg, V.; Garg, R.; Ashish. Plasma Gelsolin Levels Decrease in Diabetic State and Increase upon Treatment with F-Actin Depolymerizing Versions of Gelsolin. J. Diabetes Res. 2014, 2014, 152075. [CrossRef]

28. Peddada, N.; Sagar, A.; Garg, R. Plasma gelsolin: A general prognostic marker of health. Med Hypotheses 2012, 78, 203-210. [CrossRef]

29. Ahn, J.S.; Jang, I.-S.; Kim, D.-I.; Cho, K.A.; Park, Y.H.; Kim, K.; Kwak, C.S.; Chul Park, S. Aging-associated increase of gelsolin for apoptosis resistance. Biochem. Biophys. Res. Commun. 2003, 312, 1335-1341. [CrossRef]

30. Ji, L.; Chauhan, A.; Muthaiyah, B.; Wegiel, J.; Chauhan, V. Gelsolin Levels are Increased in the Brain as a Function of Age During Normal Development in Children That are Further Increased in Down Syndrome. Alzheimer Dis. Assoc. Disord. 2009, 23, 319-322. [CrossRef]

31. Li, G.H.; Shi, Y.; Chen, Y.; Sun, M.; Sader, S.; Maekawa, Y.; Arab, S.; Dawood, F.; Chen, M.; De Couto, G.; et al. Gelsolin regulates cardiac remodeling after myocardial infarction through DNase I-mediated apoptosis. Circ. Res. 2009, 104, 896-904. [CrossRef] [PubMed] 
32. Patel, V.B.; Zhabyeyev, P.; Chen, X.; Wang, F.; Paul, M.; Fan, D.; McLean, B.A.; Basu, R.; Zhang, P.; Shah, S.; et al. PI3K $\alpha$-regulated gelsolin activity is a critical determinant of cardiac cytoskeletal remodeling and heart disease. Nat. Commun. 2018, 9, 5390. [CrossRef] [PubMed]

33. Mahalka, A.K.; Maury, C.P.J.; Kinnunen, P.K.J. 1-Palmitoyl-2-(9'-oxononanoyl)-sn -glycero-3-phosphocholine, an Oxidized Phospholipid, Accelerates Finnish Type Familial Gelsolin Amyloidosis in Vitro. Biochemistry 2011, 50, 4877-4889. [CrossRef] [PubMed]

34. Ji, L.; Chauhan, A.; Wegiel, J.; Essa, M.M.; Chauhan, V. Gelsolin is Proteolytically Cleaved in the Brains of Individuals with Alzheimer's Disease. J. Alzheimer's Dis. 2009, 18, 105-111. [CrossRef] [PubMed]

35. Ji, L.; Chauhan, A.; Chauhan, V. Calcium induces expression of cytoplasmic gelsolin in SH-SY5Y and HEK-293 cells. Neurochem. Res. 2010, 35, 1075-1082. [CrossRef]

36. Ji, L.; Chauhan, A.; Chauhan, V. Upregulation of cytoplasmic gelsolin, an amyloid-beta-binding protein, under oxidative stress conditions: Involvement of protein kinase C. J. Alzheimer's Dis. JAD 2010, 19, 829-838. [CrossRef]

37. Greijer, A.E.; van der Groep, P.; Kemming, D.; Shvarts, A.; Semenza, G.L.; Meijer, G.A.; van de Wiel, M.A.; Belien, J.A.M.; van Diest, P.J.; van der Wall, E. Up-regulation of gene expression by hypoxia is mediated predominantly by hypoxia-inducible factor 1 (HIF-1). J. Pathol. 2005, 206, 291-304. [CrossRef]

38. Li, Q.; Ye, Z.; Wen, J.; Ma, L.; He, Y.; Lian, G.; Wang, Z.; Wei, L.; Wu, D.; Jiang, B. Gelsolin, but not its cleavage, is required for TNF-induced ROS generation and apoptosis in MCF-7 cells. Biochem. Biophys. Res. Commun. 2009, 385, 284-289. [CrossRef]

39. Tochhawng, L.; Deng, S.; Pugalenthi, G.; Kumar, A.P.; Lim, K.H.; Tan, T.Z.; Yang, H.; Hooi, S.C.; Goh, Y.C.; Maciver, S.K.; et al. Gelsolin-Cu/ZnSOD interaction alters intracellular reactive oxygen species levels to promote cancer cell invasion. Oncotarget 2016, 7, 52832-52848. [CrossRef]

40. García-Bartolomé, A.; Peñas, A.; Marín-Buera, L.; Lobo-Jarne, T.; Pérez-Pérez, R.; Morán, M.; Arenas, J.; Martín, M.A.; Ugalde, C. Respiratory chain enzyme deficiency induces mitochondrial location of actin-binding gelsolin to modulate the oligomerization of VDAC complexes and cell survival. Hum. Mol. Genet. 2017, 26, 2493-2506. [CrossRef]

41. Ugalde, C.; Hinttala, R.; Timal, S.; Smeets, R.; Rodenburg, R.J.T.; Uusimaa, J.; van Heuvel, L.P.; Nijtmans, L.G.J.; Majamaa, K.; Smeitink, J.A.M. Mutated ND2 impairs mitochondrial complex I assembly and leads to Leigh Syndrome. Mol. Genet. Metab. 2007, 90, 10-14. [CrossRef] [PubMed]

42. Rana, M.; De Coo, I.; Diaz, F.; Smeets, H.; Moraes, C.T. An out-of-frame cytochrome b gene deletion from a patient with parkinsonism is associated with impaired complex III assembly and an increase in free radical production. Ann. Neurol. 2000, 48, 774-781. [CrossRef]

43. Protasoni, M.; Pérez-Pérez, R.; Lobo-Jarne, T.; Harbour, M.E.; Ding, S.; Peñas, A.; Diaz, F.; Moraes, C.T.; Fearnley, I.M.; Zeviani, M.; et al. Respiratory supercomplexes act as a platform for complex III -mediated maturation of human mitochondrial complexes I and IV. EMBO J. 2020, 39, e102817. [CrossRef] [PubMed]

44. Bruno, C.; Martinuzzi, A.; Tang, Y.; Andreu, A.L.; Pallotti, F.; Bonilla, E.; Shanske, S.; Fu, J.; Sue, C.M.; Angelini, C.; et al. A stop-codon mutation in the human mtDNA cytochrome c oxidase I gene disrupts the functional structure of complex IV. Am. J. Hum. Genet. 1999, 65, 611-620. [CrossRef] [PubMed]

45. Campos, Y.; García-Redondo, A.; Fernández-Moreno, M.A.; Martínez-Pardo, M.; Goda, G.; Rubio, J.C.; Martín, M.A.; del Hoyo, P.; Cabello, A.; Bornstein, B.; et al. Early-onset multisystem mitochondrial disorder caused by a nonsense mutation in the mitochondrial DNA cytochrome C oxidase II gene. Ann. Neurol. 2001, 50, 409-413. [CrossRef]

46. Lobo-Jarne, T.; Pérez-Pérez, R.; Fontanesi, F.; Timón-Gómez, A.; Wittig, I.; Peñas, A.; Serrano-Lorenzo, P.; García-Consuegra, I.; Arenas, J.; Martín, M.A.; et al. Multiple pathways coordinate assembly of human mitochondrial complex IV and stabilization of respiratory supercomplexes. EMBO J. 2020, 39, e103912. [CrossRef]

47. Bourens, M.; Barrientos, A. Human mitochondrial cytochrome c oxidase assembly factor COX18 acts transiently as a membrane insertase within the subunit 2 maturation module. J. Biol. Chem. 2017, 292, 7774-7783. [CrossRef]

48. Perez-Perez, R.; Lobo-Jarne, T.; Milenkovic, D.; Mourier, A.; Bratic, A.; Garcia-Bartolome, A.; Fernandez-Vizarra, E.; Cadenas, S.; Delmiro, A.; Garcia-Consuegra, I.; et al. COX7A2L Is a Mitochondrial Complex III Binding Protein that Stabilizes the III2+IV Supercomplex without Affecting Respirasome Formation. Cell Rep. 2016, 16, 2387-2398. [CrossRef] 
49. King, M.P.; Attardi, G. Isolation of human cell lines lacking mitochondrial DNA. Methods Enzymol. 1996, 264, 304-313.

50. De Coo, I.F.; Renier, W.O.; Ruitenbeek, W.; Ter Laak, H.J.; Bakker, M.; Schägger, H.; Van Oost, B.A.; Smeets, H.J. A 4-base pair deletion in the mitochondrial cytochrome $b$ gene associated with parkinsonism/MELAS overlap syndrome. Ann. Neurol. 1999, 45, 130-133. [CrossRef]

51. Balsa, E.; Marco, R.; Perales-Clemente, E.; Szklarczyk, R.; Calvo, E.; Landázuri, M.O.; Enríquez, J.A. NDUFA4 is a subunit of complex IV of the mammalian electron transport chain. Cell Metab. 2012, 16, 378-386. [CrossRef] [PubMed]

52. D'Aurelio, M.; Gajewski, C.D.; Lenaz, G.; Manfredi, G. Respiratory chain supercomplexes set the threshold for respiration defects in human mtDNA mutant cybrids. Hum. Mol. Genet. 2006, 15, 2157-2169. [CrossRef] [PubMed]

53. Vives-Bauza, C.; Gonzalo, R.; Manfredi, G.; Garcia-Arumi, E.; Andreu, A.L. Enhanced ROS production and antioxidant defenses in cybrids harbouring mutations in mtDNA. Neurosci. Lett. 2006, 391, 136-141. [CrossRef]

54. Gusdon, A.M.; Votyakova, T.V.; Mathews, C.E. $m t-N d 2^{a}$ Suppresses Reactive Oxygen Species Production by Mitochondrial Complexes I and III. J. Biol. Chem. 2008, 283, 10690-10697. [CrossRef] [PubMed]

55. Lennicke, C.; Rahn, J.; Lichtenfels, R.; Wessjohann, L.A.; Seliger, B. Hydrogen peroxide - production, fate and role in redox signaling of tumor cells. Cell Commun. Signal. 2015, 13. [CrossRef]

56. Suhler, E.; Lin, W.; Yin, H.L.; Lee, W.M. Decreased plasma gelsolin concentrations in acute liver failure, myocardial infarction, septic shock, and myonecrosis. Crit. Care Med. 1997, 25, 594-598. [CrossRef]

57. Kulakowska, A.; Drozdowski, W.; Sadzynski, A.; Bucki, R.; Janmey, P.A. Gelsolin concentration in cerebrospinal fluid from patients with multiple sclerosis and other neurological disorders. Eur. J. Neurol. 2008, 15, 584-588. [CrossRef]

58. Osborn, T.M.; Verdrengh, M.; Stossel, T.P.; Tarkowski, A.; Bokarewa, M. Decreased levels of the gelsolin plasma isoform in patients with rheumatoid arthritis. Arthritis Res. Ther. 2008, 10. [CrossRef]

59. Mounzer, K.C.; Moncure, M.; Smith, Y.R.; Dinubile, M.J. Relationship of admission plasma gelsolin levels to clinical outcomes in patients after major trauma. Am. J. Respir. Crit. Care Med. 1999, 160, 1673-1681. [CrossRef]

60. Smith, D.B.; Janmey, P.A.; Sherwood, J.A.; Howard, R.J.; Lind, S.E. Decreased plasma gelsolin levels in patients with Plasmodium falciparum malaria: A consequence of hemolysis? Blood 1988, 72, 214-218. [CrossRef]

61. Maldonado, E.N. VDAC-tubulin, an anti-Warburg pro-oxidant switch. Front. Oncol. 2017, 7, 4. [CrossRef] [PubMed]

62. Bell, E.L.; Klimova, T.A.; Eisenbart, J.; Moraes, C.T.; Murphy, M.P.; Budinger, G.R.S.; Chandel, N.S. The Qo site of the mitochondrial complex III is required for the transduction of hypoxic signaling via reactive oxygen species production. J. Cell Biol. 2007, 177, 1029-1036. [CrossRef] [PubMed]

63. Blázquez, A.; Gil-Borlado, M.C.; Morán, M.; Verdú, A.; Cazorla-Calleja, M.R.; Martín, M.A.; Arenas, J.; Ugalde, C. Infantile mitochondrial encephalomyopathy with unusual phenotype caused by a novel BCS1L mutation in an isolated complex III-deficient patient. Neuromuscul. Disord. 2009, 19, 143-146. [CrossRef] [PubMed]

64. Korzeniewski, B. Effects of OXPHOS complex deficiencies and ESA dysfunction in working intact skeletal muscle: Implications for mitochondrial myopathies. Biochim. Biophys. Acta 2015, 1847, 1310-1319. [CrossRef] [PubMed]

65. Valsecchi, F.; Esseling, J.J.; Koopman, W.J.H.; Willems, P.H.G.M. Calcium and ATP handling in human NADH: Ubiquinone oxidoreductase deficiency. Biochim. Biophys. Acta 2009, 1792, 1130-1137. [CrossRef]

(C) 2020 by the authors. Licensee MDPI, Basel, Switzerland. This article is an open access article distributed under the terms and conditions of the Creative Commons Attribution (CC BY) license (http://creativecommons.org/licenses/by/4.0/). 